\title{
Review Article \\ Dendrimers as Carriers for siRNA Delivery and Gene Silencing: A Review
}

\author{
Jiangyu Wu, Weizhe Huang, and Ziying He \\ School of Materials Science \& Engineering, Wuhan Institute of Technology, 693 Xiong Chu Road, Wuhan 430073, China \\ Correspondence should be addressed to Jiangyu Wu; jiangy.wu@gmail.com
}

Received 27 August 2013; Accepted 19 September 2013

Academic Editors: D. H. Dinh and K. Weber

Copyright (C) 2013 Jiangyu Wu et al. This is an open access article distributed under the Creative Commons Attribution License, which permits unrestricted use, distribution, and reproduction in any medium, provided the original work is properly cited.

\begin{abstract}
RNA interference (RNAi) was first literaturally reported in 1998 and has become rapidly a promising tool for therapeutic applications in gene therapy. In a typical RNAi process, small interfering RNAs (siRNA) are used to specifically downregulate the expression of the targeted gene, known as the term "gene silencing." One key point for successful gene silencing is to employ a safe and efficient siRNA delivery system. In this context, dendrimers are emerging as potential nonviral vectors to deliver siRNA for RNAi purpose. Dendrimers have attracted intense interest since their emanating research in the 1980s and are extensively studied as efficient DNA delivery vectors in gene transfer applications, due to their unique features based on the well-defined and multivalent structures. Knowing that DNA and RNA possess a similar structure in terms of nucleic acid framework and the electronegative nature, one can also use the excellent DNA delivery properties of dendrimers to develop effective siRNA delivery systems. In this review, the development of dendrimer-based siRNA delivery vectors is summarized, focusing on the vector features (siRNA delivery efficiency, cytotoxicity, etc.) of different types of dendrimers and the related investigations on structure-activity relationship to promote safe and efficient siRNA delivery system.
\end{abstract}

\section{Introduction}

Gene therapy is now a potential tool to handle stubborn diseases such as cancer and heredopathia to which ordinary treatments are noneffective. In addition to DNA-involved gene transfer, RNA interfering (RNAi) provides another approach by employing RNA as the gene therapy reagent. Since its first report in 1998, RNAi has rapidly become a powerful strategy both in basic research and for developing efficient therapeutics [1-3]. In the general RNAi process, long transcripts of double-stranded RNA (dsRNA) are cleaved into small interfering RNAs (siRNAs) by the help of an endoribonuclease Dicer. The resulting siRNA molecule is then loaded onto the RNA-induced silencing complex (RISC) to form RISC-siRNA complex. After activation, the siRNA is unwrapped and one of the two strands is released, resulting in an activated form of RISC with a single-stranded RNA. This RISC-RNA complex then binds to mRNA homologous in sequence to the siRNA by base-pairing recognition and guides its sequence-specific degradation and consequently knocks down the expression of the corresponding protein
(Figure 1). This procedure is also known as gene silencing that is highly effective and specific, because one nucleotide mismatch between the target mRNA and the siRNA can prevent the recognition and thus the silencing process.

The successful development of RNAi for clinical applications depends on the efficient and safe vectors to deliver siRNAs into target cells, having to overcome the extracellular and intracellular barriers [4]. There are several key requirements for siRNA vectors [5]: (1) to protect siRNA from degradation during systemic circulation; (2) to transport siRNA to target sites and avoid nonspecific delivery; (3) to promote cellular uptake and subsequent endosomal escape; and (4) to release siRNA and make siRNA readily accessible to the cellular RNAi machinery to permit an effective gene silencing process. Because DNA and siRNA possess similar molecular structure and physicochemical properties, vectors developed for DNA may also be applied for siRNA delivery. As in DNA-based gene transfer, virus-derived carriers have shown high efficiency to deliver siRNA to host cells by taking advantage of intracellular trafficking machineries. However, due to several drawbacks such as high cost of production and 


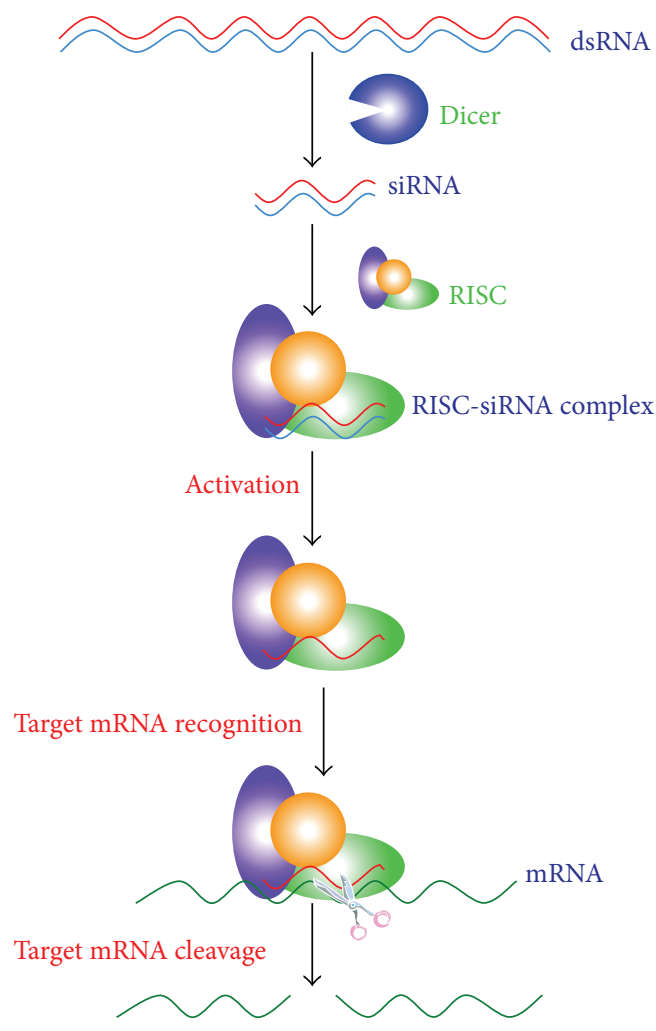

FIGURE 1: The mechanism of RNA interference. For details see the context and related references.

safety concerns, also as in DNA case, nonviral siRNA vectors have attracted more and more attentions. These vectors typically possess cationic nature (e.g., cationic cell penetrating peptides, cationic polymers, dendrimers, and cationic lipids) and complex siRNA by electrostatic interaction [4]. Among these cationic vectors, dendrimers demonstrate a special class because they are synthesized step by step and as a consequence their molecular architecture can thus be precisely designed and controlled. The typical structure of a dendrimer molecule contains three parts: (1) a central core to define the interior size and the branch number/direction, (2) the repetitive branch units to regulate the generation $(\mathrm{G})$, the molecular size and flexibility, and (3) the terminal groups to present the chemical property and the interaction possibility. Up to now, a lot of research work concerning nonviral siRNA delivery use dendrimers as the vectors due to their unique and adaptable chemistry. According to the database of ISI web of knowledge, there are increasing papers published on dendrimer-based siRNA delivery from 2005 to 2012 (Figure 2(a)). In viewpoint of dendrimer type, as shown in Figure 2(b), many kinds of dendrimers have been explored for siRNA delivery, including poly(amidoamine) dendrimers [6-52], poly(propylene imine) dendrimers [5356], carbosilane dendrimers [57-64], poly(L-lysine) dendrimers [65-67], triazine dendrimers [68-70], polyglycerolbased dendrimers [71-73], nanocarbon-based dendrimers [74-77], and other types of dendrimers [71, 78-81]. Readers can also find a few review papers referring to dendrimerbased siRNA vectors in the subject of barriers and carriers for siRNA therapeutics [4] and dendrimers [5, 57, 82-86], polymers [87-90], nanotechnologies [91-93], and nonviral vectors for siRNA delivery [94-96].

In this review, siRNA vectors based on different types of dendrimers are summarized, focusing on the vector features (siRNA delivery ability, cytotoxicity, etc.) and the related investigations on structure-activity relationship to develop safe and efficient siRNA delivery systems.

\section{Poly(amidoamine) Dendrimers}

In 1985, Tomalia et al. first reported the synthesis and characterization of poly(amidoamine) (PAMAM) dendrimers using ammonium $\left(\mathrm{NH}_{3}\right)$ or ethylenediamine (EDA) as the core [97] (Figures 3(a), and 3(b)). PAMAM dendrimer is now the most important type in dendrimer family, and many kinds of PAMAM dendrimers with different core units and terminal groups have been developed. In 1993, Haensler and Szoka first reported the research on PAMAM dendrimer-based gene transfection [98]. PAMAM dendrimers can interact and compact DNA plasmid by electrostatic interaction to form nanocomposite favoring the cell uptake process and release DNA in the cell through "sponge effect" thanks to the buffering ability of the tertiary amine groups in the branch units $[98,99]$. Since then, the excellent DNA complexation ability and the fine tunability of PAMAM dendrimers aroused a lot of creative work focusing on it. Today gene transfer kits such as PolyFect and SuperFect, which are based on activated dendrimer technology optimized for the transfection of DNA, are commercially available. Because of their promising activity in DNA-based gene transfer study, PAMAM dendrimers have been also investigated in siRNA delivery. It is worth noting that PAMAM dendrimers are also the prominent species utilized in dendrimer-based siRNA delivery research (Figure 2(b)).

2.1. PAMAM Dendrimers without Modification. In 2009, Perez et al. investigated the complex formation between EDAcore PAMAM dendrimers and siRNA as a function of three factors: the ionic strength of the medium, the dendrimer generation, and the N/P ratio (nitrogen in PAMAM/phosphate in siRNA). The siRNA/G7 (G for generation) complexes produced the highest inhibition of enhanced green fluorescent protein (EGFP) expression both in nonphagocytic cells (T98G-EGFP) and phagocytic cells (J774-EGFP) in $\mathrm{NaCl}$ lacking medium [6]. In addition, these complexes were internalized at higher rates by T98G but induced lower silencing than in J774 cells. The higher silencing activity of siRNA dendriplexes in J774 cells was ascribed to the contribution of clathrin-dependent and caveolin-dependent endocytosis while only the latter happened in T98G cells [7]. Recently, this group incorporated ${ }^{32} \mathrm{P}$-labeled siRNA/G7 PAMAM dendriplex into in situ forming mucoadhesive gels. Increased brain radioactivity could be achieved through intranasal administration of the formed gels to rats [8]. In another group Jensen et al. elucidated the self-assembly process between siRNA and different generation of PAMAM dendrimers. The G4 and G7 dendrimers displayed equal 


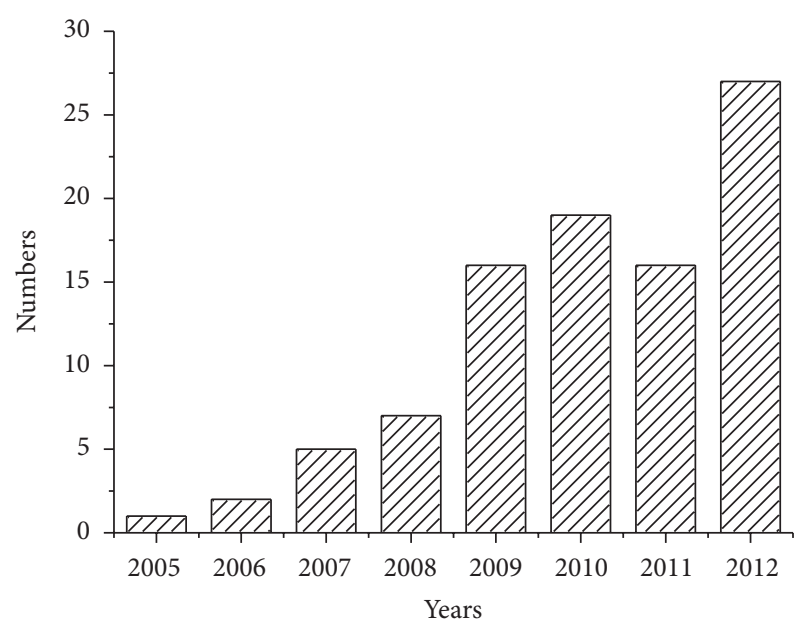

(a)

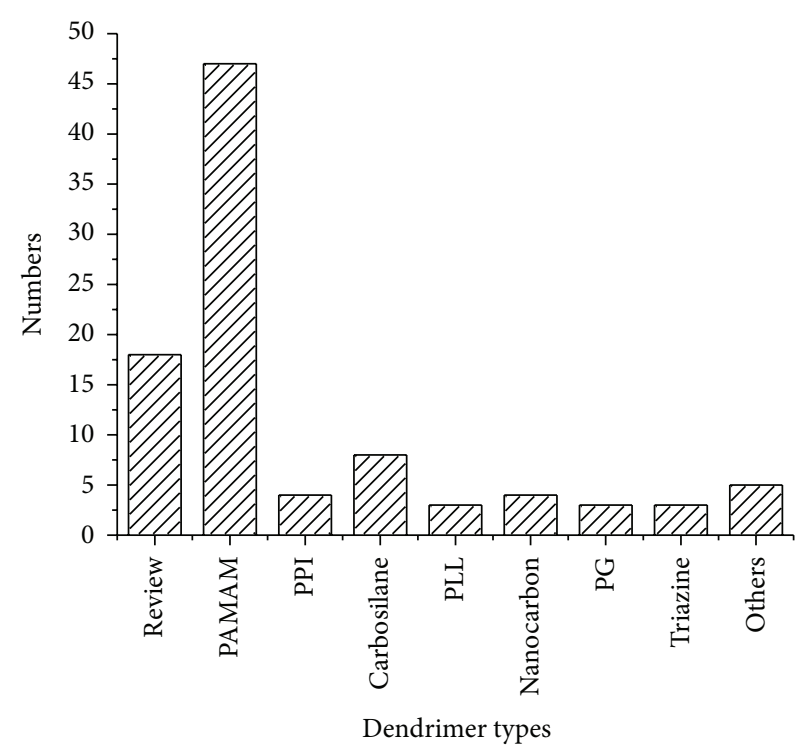

(b)

FIgURE 2: The number of the literature published concerning dendrimer-based siRNA delivery (data from ISI web of knowledge, from 2005 to 2012). (a) Distribution by years (b) Distribution by dendrimer types.

efficiencies for dendriplex formation, whereas G1 dendrimer lacked this ability [9]. Later, they identified various polymeric nanocarriers for anti-TNF- $\alpha$ siRNA with optimal efficacy and minimal off-target effects in vitro. PAMAM dendrimers mediated high gene silencing with minor toxicity and were therefore expected to be suitable siRNA delivery systems in vivo [10]. In 2012, Monteagudo et al. demonstrated that siRNA/G1 PAMAM dendriplex decreased both p42-MAPK mRNA and protein levels and could potentiate the antitumoral activity of anticancer drugs [11].

2.2. PAMAM Dendrimers with Surface Modification. There are basically two means to improve the biological performance of PAMAM dendrimer-base siRNA delivery system: (1) surface functionalization with biocompatible molecules or targeting units and (2) molecular structure regulation with new core unit. In 2007 Hollins et al. reported that PAMAM dendrimers differing in structural architecture could lead to an approximately 10 -fold variation in anti-EGFR (epidermal growth factor receptor) siRNA activity [12].

In 2005, Kang et al. conjugated Tat, a cell penetrating peptide, to EDA-core PAMAM G5 dendrimer and evaluated the biological activity of dendrimers and dendrimerpeptide composites in siRNA delivery. However, these composites were poorly effective for delivery of siRNA and the reason was not clear [13]. Tsutsumi et al. evaluated in 2006 the $\alpha$-cyclodextrin conjugated G3 PAMAM dendrimer $(\alpha-\mathrm{CDE})$ as a siRNA carrier [14]. The ternary complex of $\mathrm{pDNA} / \mathrm{siRNA} / \alpha$-CDE showed higher siRNA sequencespecific gene silencing effects without off-target effects than those of commercial transfection reagents such as Lipofectamine2000 TransFast and Lipofectin in various cells [14, 15]. In 2011, Arima et al. examined extensively the biological properties of $\alpha$-CDE conjugate including physicochemical properties, serum resistance, in vitro RNAi effects, and so forth. The siRNA complex with $\alpha$-CDE conjugate showed silencing effects against Lamin $\mathrm{A} / \mathrm{C}$ and Fas expression with negligible cytotoxicity and hemolytic activity in cells stably expressing pGL3 firefly luciferase gene (Colon-26-luc cells and NIH3T3-luc cells) [16]. Later, Arima's group conjugated folate-poly(ethylene glycol) (PEG) or lactose appendix to $\alpha$ $\mathrm{CDE}$ and evaluated their siRNA transfer activities, to folate receptor (FR)-overexpressing cancer cells and for the treatment of familial amyloidotic polyneuropathy, respectively [17-19].

In 2008 Patil et al. evaluated an internally quaternized and surface-acetylated G4 PAMAM dendrimer (QPAMAMNHAc) for siRNA delivery. This QPAMAM-NHAc dendrimer had modified neutral surface for low cytotoxicity and enhanced cellular internalization and possessed cationic charges inside the dendrimer in order to compact nanoparticles to protect siRNA from degradation [20]. Later Patil et al. synthesized a similar PAMAM molecule (QPAMAM-OH) and conjugated it with a synthetic analog of luteinizing hormone-releasing hormone (LHRH) as cancer targeting moiety. Both nontargeted and targeted dendrimer/siRNA complexes formed compact nanoparticles, exhibited low cytotoxicity, and efficiently penetrated cancer cells in vitro. However, only the targeted dendrimer-siRNA complex was able to substantially decrease the expression of a targeted BCL2 gene [21]. In 2011 this group developed a triblock poly(amidoamine)-poly(ethylene glycol)-poly-Llysine (PAMAM-PEG-PLL) carrier for siRNA delivery. The complexes formed by the siRNA and the carriers were stable in human plasma and effectively taken up by cancer cells and induced the knockdown of the target BCL2 gene [22].

In 2009 Waite et al. investigated acetylated PAMAM dendrimers for siRNA delivery. Surface acetylation of PAMAM 


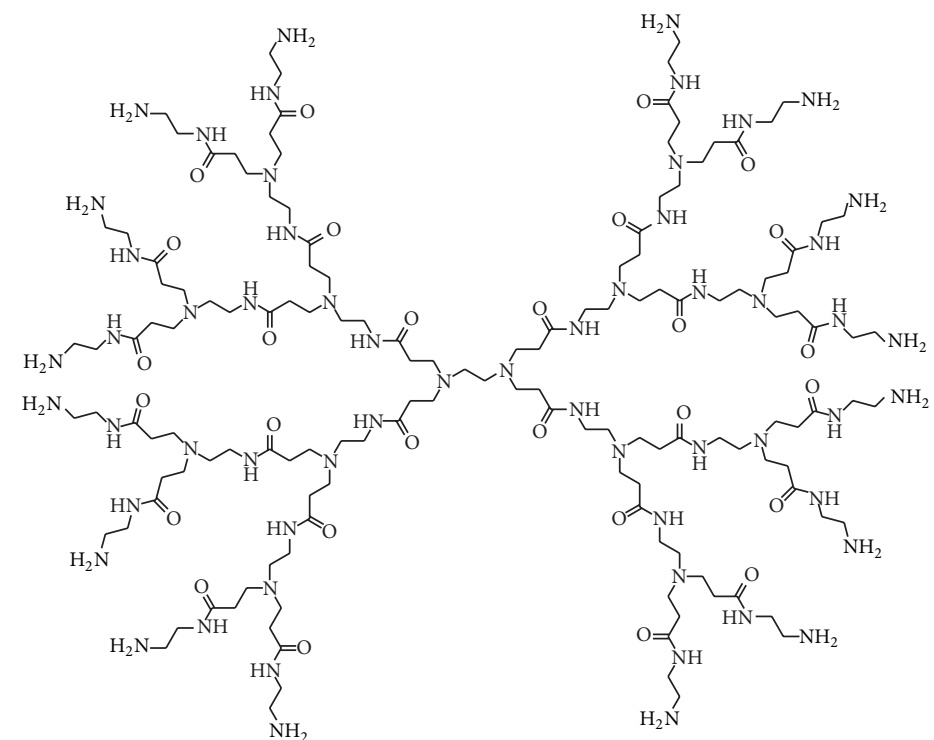

(a)

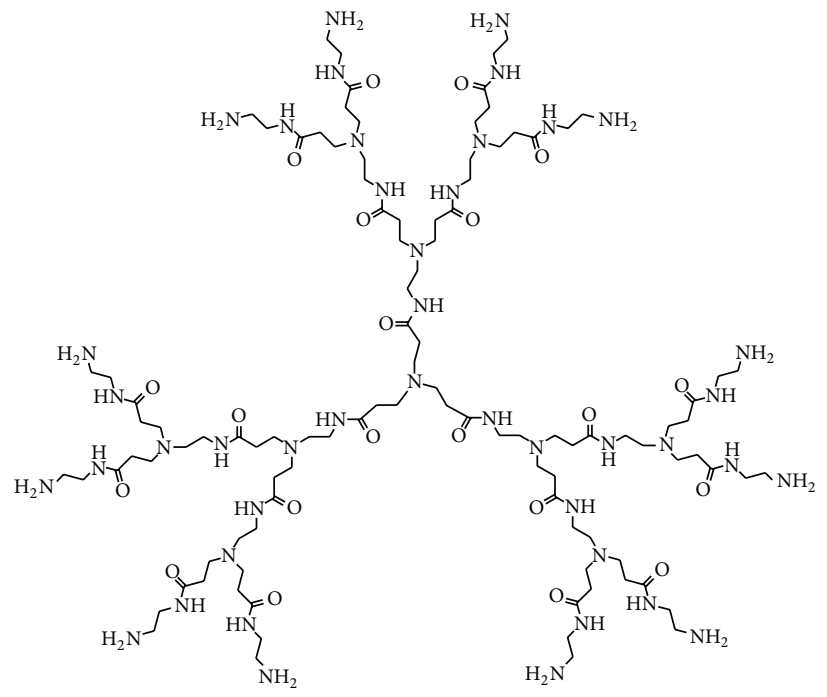

(b)

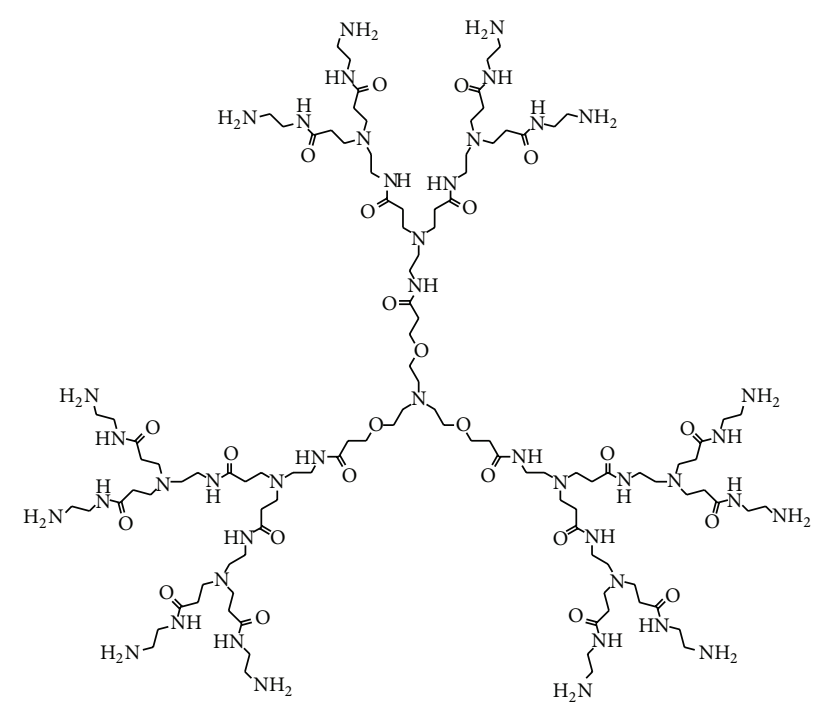

(c)

FIGURE 3: Molecular structure of generation 2 PAMAM dendrimer with (a) ethylenediamine (EDA) core, (b) ammonium $\left(\mathrm{NH}_{3}\right)$ core, and (c) triethanolamine (TEA) core.

dendrimers reduced their cytotoxicity to U87 cells and promoted the release of siRNA from dendrimer/siRNA complexes. Twenty percent acetylation of primary amines of PAMAM could maintain the siRNA delivery efficiency of unmodified PAMAM, but higher degrees of amine neutralization decreased the gene silencing efficiency of PAMAM dendrimer vectors [23]. These researchers also modified G5 PAMAM dendrimer with cyclic RGD targeting peptides, studied the effect of RGD density on cell-free binding affinities and cellular internalization, and evaluated their siRNA delivery ability [24, 25]. While modest siRNA delivery was observed in U87 cells using either PAMAM or PAMAMRGD conjugates, the delivery of siRNA through threedimensional multicellular spheroids of U87 cells was enhanced only using PAMAM-RGD conjugates, presumably by interfering with integrin-ECM contacts present in a threedimensional tumor model [24].

Elsabahy et al. developed in 2009 polyion complex micelles (PICMs) to deliver siRNA. The PICMs consisted of a PAMAM dendrimer/siRNA core, a detachable poly(ethylene glycol)-block-poly(propyl methacrylateco-methacrylic acid) (PEG-b-P(PrMA-co-MAA)) shell and the monoclonal antibody fragment conjugated at the surface. These $\mathrm{pH}$-responsive targeted PICMs exhibited a higher transfection activity than nontargeted micelles or commercial PAMAM dendrimers and their nonspecific cytotoxicity was lower than that of unmodified PAMAM [26]. Felber et al. showed that these PICMs loosed their shell and released 
the PAMAM/siRNA core under mildly acidic conditions in the endosomal compartment. After being decorated with an antibody unit against the transferrin receptor (anti-CD71), the PICM were taken up by cells through receptor-mediated endocytosis, and $\mathrm{Bcl}-2 \mathrm{mRNA}$ and protein levels were largely reduced [27].

In 2010 Yuan et al. reported an epidermal growth factor (EGF)-containing PAMAM G4 dendrimer vector labeled with quantum dots for targeted imaging and siRNA delivery. The intracellular localization of the dendrimer/siRNA complex was achieved in an EGFR-dependent manner, and the knockdown of expression was observed by using yellow fluorescent protein (YFP) siRNA [28]. Dutta et al. explored neutral dendrosomes by encapsulating dendrimer/siRNA complexes within the lipid layers, to prevent free amino groups from contacting with cell membranes, resulting in lowering the cytotoxicity while maintaining the green fluorescence protein (GFP) knockdown efficiency of unmodified dendrimer/siRNA complex [29]. Kim et al. synthesized an arginine ester of PAMAM dendrimer (e-PAM-R), which was degradable under physiological conditions. The use of ePAM-R for siRNA delivery was demonstrated by gene knockdown after transfecting high mobility group box-1 (HMGB1, a cytokine-like molecule) siRNA into $\mathrm{H}_{2} \mathrm{O}_{2}$ - or NMDA-treated primary cortical cultures. This dendrimer achieved high siRNA transfection levels in primary cortical cultures and in normal rat brain and showed low cytotoxic effect on primary neuronal cells at relatively high doses and long incubation period [30]. Later, intranasal delivery of HMGB1 siRNA with e-PAM-R as carrier efficiently knocked down the target gene in brain regions including the prefrontal cortex and striatum and suppressed infarct volume in the postischemic rat brain with maximal reduction of $42.8 \pm 5.6 \%$ at 48 hours after 60 minutes middle cerebral artery occlusion (MCAO) [31]. In 2012, Liu et al. described a neutral cross-linked dendritic system by replacing the terminal amines of PAMAM dendrimers with hydrazide groups and $\mathrm{N}$-acetylgalactosamine (GalNAc) ligands and used glutaraldehyde as the cross-link reagent. In vitro cellular uptake and RNAi experiments showed that the cross-linked dendritic systems with an appropriate level of GalNAc composition effectively interacted with HepG2 cells and inhibited the expression of a luciferase reporter gene [32].

Recently, Tang et al. studied the siRNA delivery activities of MPEG-5000 modified G5/G6 PAMAM dendrimer in vitro and in vivo. The delivery of GFP-siRNA using PEGmodified dendrimers achieved knockdown of adenovirusmediated GFP expression in both transiently adenovirus infected C57BL/6 mice and GFP transgenic mice [33]. Han et al. employed polysaccharide hyaluronic acid (HA) functionalized G5 PAMAM dendrimers as vectors for transporting doxorubicin (DOX) and major vault protein (MVP) targeted siRNA. As a result of MVP expression knockdown, the codelivery system allowed efficient DOX access to the nucleus and exhibited much more cytotoxicity than siRNA absent case [34].

2.3. PAMAM Dendrimers with New-Core Incorporation. Besides the surface modification on traditional (e.g., EDAcore or $\mathrm{NH}_{3}$-core) PAMAM dendrimer, optimization of the

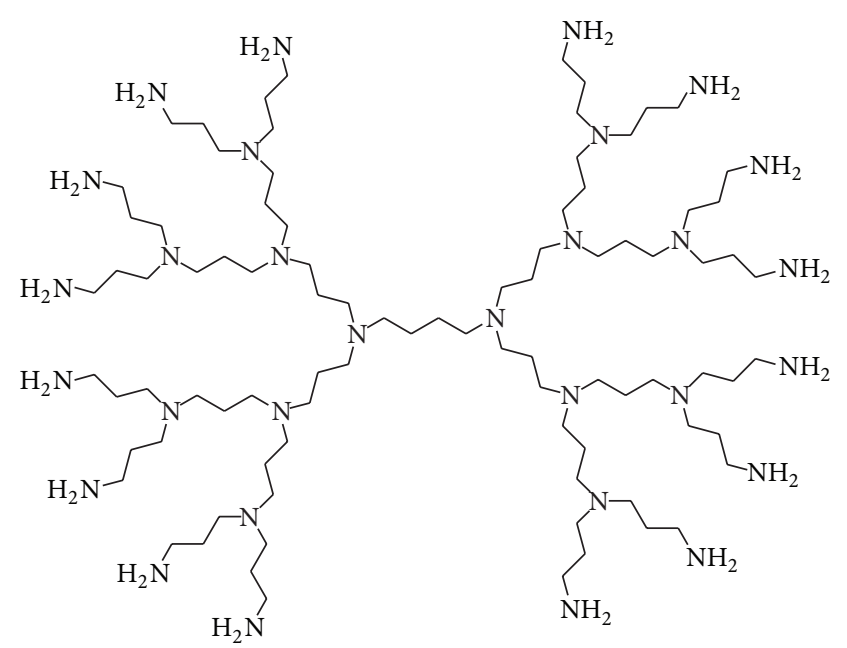

Figure 4: Poly(propylene imine) (PPI) G3 dendrimer.

molecular structure from the starting synthesis provides an alternative strategy to improve the performance of PAMAM dendrimers. In 2005, Wu et al. developed a series of PAMAM dendrimers with a triethanolamine (TEA) core (Figure 3(c)) [100]. These TEA-core PAMAM dendrimers were shown to interact with siRNA, forming stable nanoparticles to protect siRNA from degradation by RNase and to favor the cellular uptake process [35]. The potential of these flexible dendrimers as vectors for siRNA delivery were demonstrated, both in a luciferase model [36] and in a prostate cancer model [37]. The knockdown of heat-shock protein 27 (Hsp27) and the caspase-dependent apoptosis-induced anticancer activity were observed with higher generation dendrimers [37]. These dendrimers also efficiently delivered siRNA into human $\mathrm{T}$ cells and primary peripheral blood mononuclear cells (PBMC) cells and displayed an effective gene silencing effect [38]. By using sticky siRNA molecules bearing complementary An/Tn $3^{\prime}$-overhangs, G5 TEA-core PAMAM dendrimer was shown to effectively deliver siRNA to a prostate cancer model and achieve gene silencing of Hsp27 and anticancer activity in vitro and in vivo [39]. Recently, Peng's group synthesized an amphiphilic dendrimer molecule bearing a hydrophobic alkyl chain and a hydrophilic PAMAM dendron with eight terminal primary amines. This molecule combined the advantages of lipid and dendrimer vectors and was shown to deliver Hsp27 siRNA in a castration-resistant prostate cancer model and produce gene silencing and anticancer activity [40].

In 2011 Deng et al. promoted a dendritic structure consisting of a $\beta$-cyclodextrin core and PAMAM dendron arms. These dendrimers exhibited high siRNA transfection efficiency and low cytotoxicity in fibroblast cells [41]. In the same year, Rodrigo et al. synthesized a hybrid dendrimer that combined a conjugated rigid polyphenylenevinylene (PPV) core with the flexible PAMAM branches at the surface [42]. The G1 dendrimer was shown to be an efficient and nontoxic vector to deliver a specific siRNA to rat cerebellar granular neurons, to decrease cofilin-1 protein levels and to modulate actin 


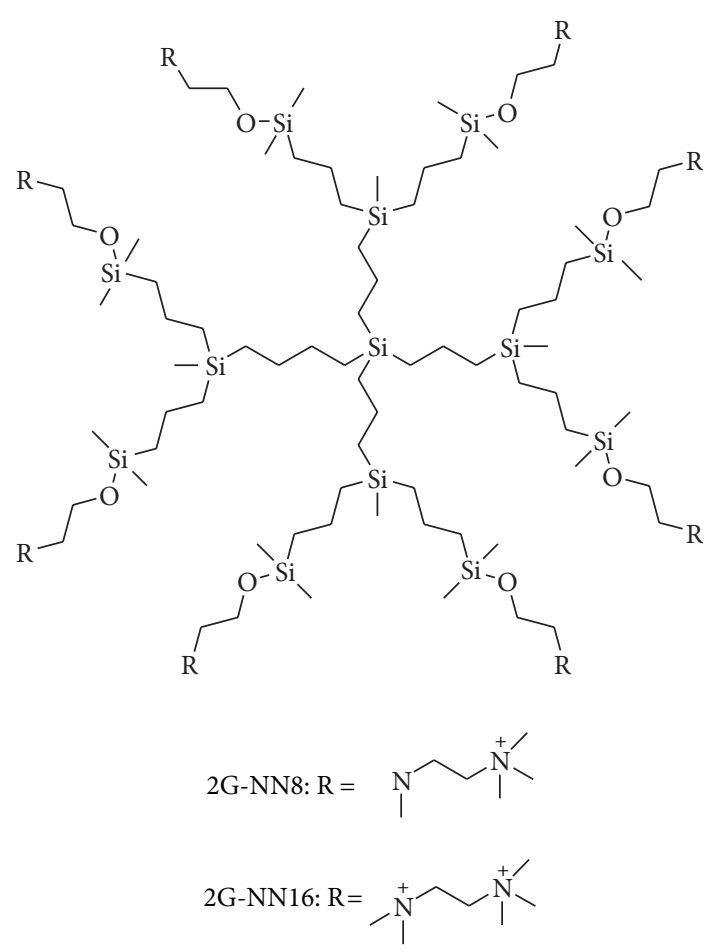

Figure 5: Carbosilane (CBS) dendrimers.

remodeling in these neurons [42]. Later, Pérez-Carrión et al. reported that these dendrimers were very efficient to deliver siRNA to rat cortical neurons, leading to almost complete removal of the target protein Beclin 1 [43]. Recently, Ceña's group compared the molecular simulation of siRNA/PPVPAMAM complex and their experimental physicochemical parameters and biological effects. The results suggested that a favorable equilibrium between a strong binding and the ability to release siRNA is very important for the carriers to exert a potent transfection activity [44]. In 2012, Zhang et al. demonstrated a siRNA vector based on PAMAM dendrimers with a pentaerythritol derivative core (PD dendrimer). G5 PD dendrimer showed effective luciferase gene silencing and the inhibition experiments suggested that clathrinmediated endocytosis was the principle endocytic pathway for G5 PD dendrimer/siRNA complex to enter the cell [45].

2.4. PAMAM Dendrimers with Computer Simulation. In order to better understand the dendrimer-based siRNA delivery, researchers preceded also modeling investigations focusing on the interaction between PAMAM dendrimers and siRNA [86]. In 2008 Posocco et al. studied the complex between PAMAM G4 dendrimer and GL3 siRNA by molecular dynamics (MD) simulations. As obtained from the application of the MM/PBSA approach, the free energy of binding between siRNA and its vector was clearly dominated by electrostatic interactions [46]. Vasumathi and Maiti investigated in 2010 the complexation behavior of siRNA with PAMAM G3/G4 dendrimers through fully atomistic molecular dynamics simulations together with free energy calculations and inherent structure determination. The results showed that the binding energy between siRNA and dendrimer increased with the dendrimer generation [47]. Pavan et al. studied the molecular requirements of the interaction between siRNA and PAMAM dendrimers of different generations by the combination of molecular simulation and experimental approaches. By applying the MM/PBSA methodology, the authors quantified the affinity between a model siRNA and G4 G6 PAMAM dendrimers. The MD trajectory demonstrated the trends of siRNA to partially penetrate inside the dendrimer structure for each generation both at acidic and neutral $\mathrm{pH}$. However, the biggest part of the siRNA double helix still remained outside the dendrimer [48]. In 2010 Pavan et al. reported a molecular dynamic study to explore the various behaviors of PAMAM dendrimers of different generations when binding siRNA. The simulations showed that the molecular flexibility of PAMAM dendrimers was very important in the binding process, which was controlled by the regulation between enthalpy and entropy of binding. The binding ability of dendrimers to siRNA strongly depended on the dendrimer generation and the $\mathrm{pH}$ value related to backfolding. G4 dendrimer exhibited excellent adaptability to siRNA while G6 behaved like a rigid sphere with a loss in the binding affinity. In addition, G5 showed a hybrid effect of the rigid and flexible aspects, with its properties depending on the $\mathrm{pH}$ value [49]. Jensen et al. studied the self-assembly process between siRNA and G7 PAMAM dendrimer and characterized the resulting complexes in aqueous solution using structural and calorimetric methods combined with MD simulations. Both the experimentally determined values of thermodynamics and the complex size were in close accordance with the results from computational simulations [50]. In 2012, Karatasos et al. studied the complex formation between PAMAM dendrimers with different core units and siRNA by computer simulations. They compared the complexation from PAMAM dendrimers having $\mathrm{NH}_{3}$ and TEA as cores and the results supported that the TEA-core PAMAM dendrimers bind siRNA more efficiently than $\mathrm{NH}_{3}$-core dendrimers by taking advantage of the better flexibility [51]. Nandy et al. recently reported the interactions and binding modes of siRNA with PAMAM dendrimers by utilizing fully atomistic simulations. The results suggested that the complexation of siRNA with various generations of dendrimers was governed by electrostatic interactions and the size and binding energy of the complex increase with dendrimer generation [52].

\section{Poly(propylene imine) Dendrimers}

Poly(propylene imine) (PPI) dendrimers (Figure 4) are another class of dendrimers that have been investigated in groups of Minko and He for their siRNA delivery potential [53-56]. In 2009, Taratula et al. modified PPI/siRNA complex with dithiol-containing cross-linker molecules followed by PEG coating, and an analog of LHRH peptide was conjugated to the end of PEG to direct the complexes specifically 


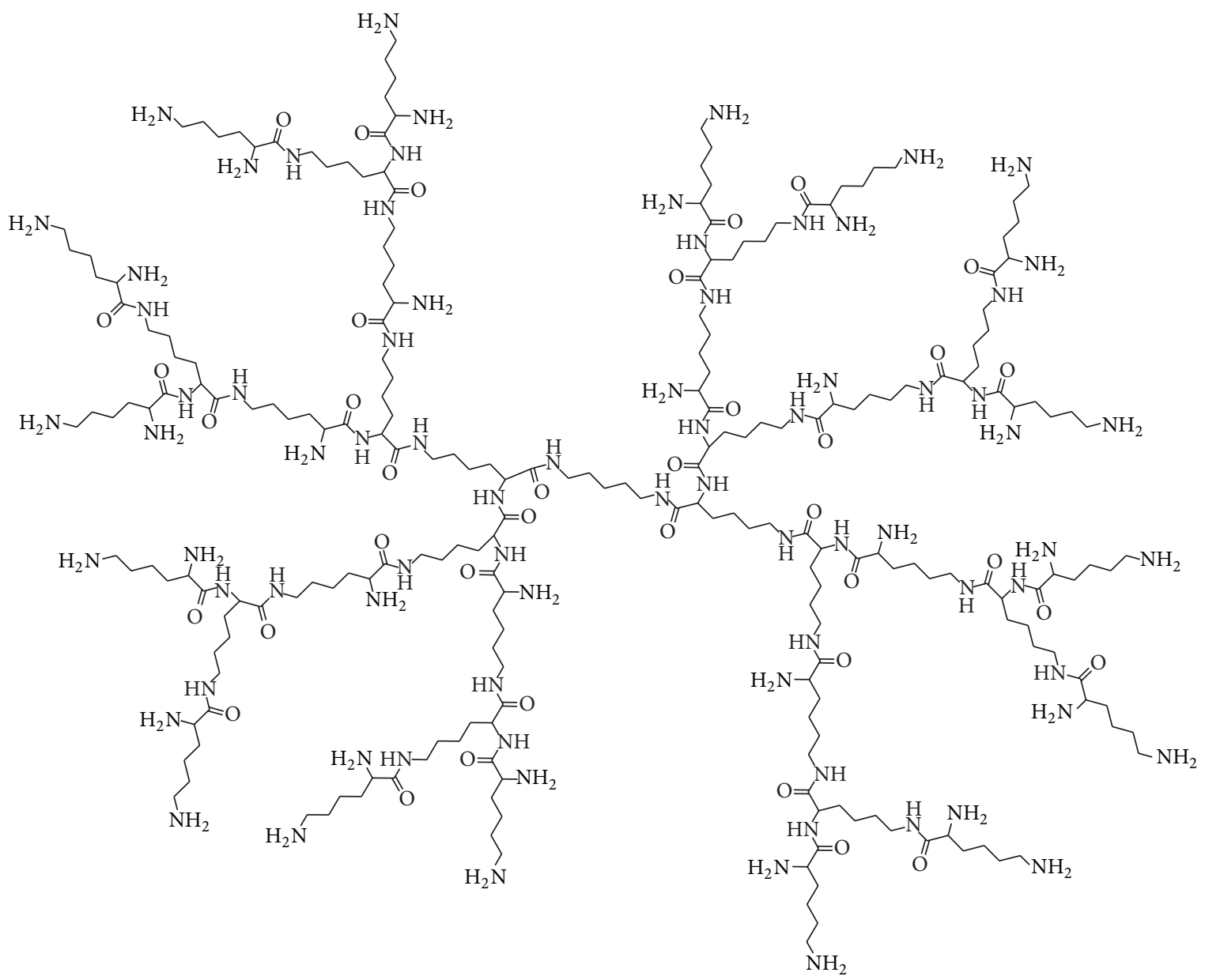

Figure 6: Poly(L-lysine) (PLL) G3 dendrimers.

to the cancer cells. The biological assay showed that this modification and targeting approach improved the complex stability in plasma and intracellular bioavailability and promoted their tumor-specific uptake, accumulation in the cytoplasm of cancer cells, and efficient gene silencing [53]. Later, Chen et al. developed a novel way to compact and deliver siRNA with low generation PPI dendrimers by using gold nanoparticles (AuNP) as a "labile catalytic" packaging agent. The AuNP helped G3 dendrimers to compact siRNA into discrete nanoparticles but were not included in the final PPI dendrimer/siRNA complexes. The efficiency of mRNA silencing by this approach was even higher than that with PPI G5 dendrimers [54]. In 2011 Taratula et al. reported that G4 and G5 PPI dendrimers effectively initiated the complexation of siRNA into nanoparticles when compared with lower generations of dendrimers (G2 and G3). The formed PPI/siRNA complexes enhanced the cellular internalization of siRNA and improved the knockdown of targeted mRNA expression in A549 human lung cancer cells. Since G5 dendrimer has larger size and higher positive charge density than G4 and thus provides higher toxicity, G4 dendrimer showed better efficacy in terms of dendrimer/siRNA complex formation, intracellular siRNA internalization, and sequence-specific gene silencing [55]. In addition, the authors developed siRNA vectors based on PPI G5 dendrimers and superparamagnetic iron oxide nanoparticles, together with incorporation of PEG coating and cancer-specific targeting peptide LHRH conjugation. This modification of PPI dendrimer/siRNA complex improved its serum stability and selective internalization into cancer cells and increased the efficiency of targeted gene silencing in vitro [56].

\section{Carbosilane Dendrimers}

Carbosilane dendrimers (CBD, Figure 5) have been investigated as siRNA delivery vectors since 2008 [57-64]. Weber et al. firstly characterized carbosilane dendrimers as effective carriers of siRNA to human immunodeficiency virus (HIV)infected lymphocytes. CBD bound siRNA via electrostatic interactions and were resistant to siRNA degradation by RNase. CBD/siRNA complex transfected lymphocytes and was shown to silence glyceraldehyde 3-phosphate dehydrogenase (GAPDH) expression and reduce HIV replication in human leukemia $\mathrm{T}$ lymphocytes and PBMC with low cytotoxicity [58]. Later Gras et al. investigated global 


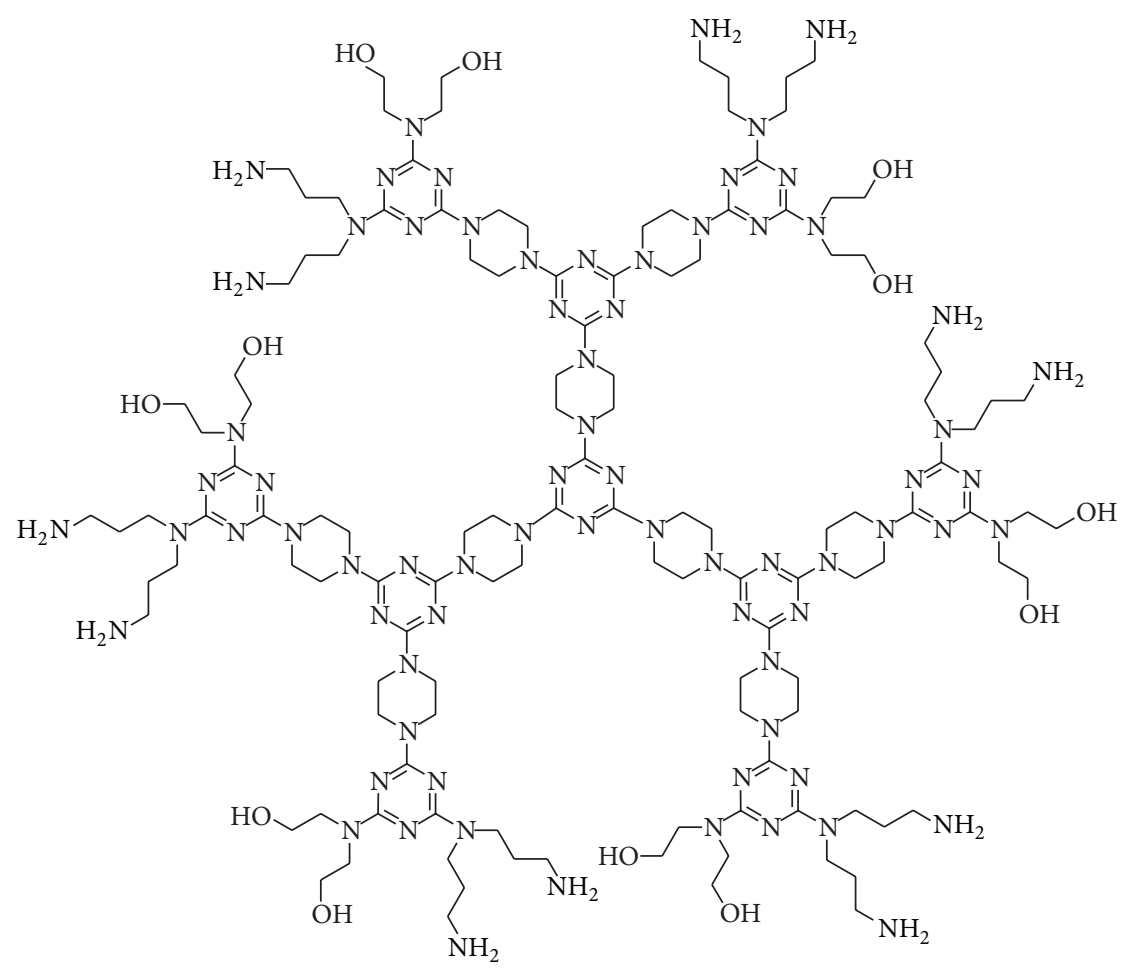

FIGURE 7: Triazine G2 dendrimers with terminal amine and hydroxyl groups.

gene expression profiles in human primary macrophages in culture with amino-terminating 2G-NN16 dendrimer (Figure 5). Exposing macrophages to this dendrimer or dendrimer/siRNA complex caused multiple gene expression changes, principally affecting immune system, proliferation, and transcription regulation pathways, but no specific action of random siRNA was detected [59]. Posadas et al. reported that carbosilane dendrimer 2G-NN16 delivered specific siRNA to neurons and selectively blocked HIF1- $\alpha$ synthesis with similar efficiency to that achieved by viral vectors [60]. Later Jiménez et al. evaluated the $2 \mathrm{G}-\mathrm{NN} 16$ as a vector for delivering siRNA to HIV-infected human astrocytes. There was no cytotoxicity in HIV-infected or noninfected human astrocytoma cells when treated with up to $24 \mu \mathrm{g} / \mathrm{mL}$ of 2G-NN16 dendrimer or siRNA/2G-NN16 complexe and the complex successfully transfected human astrocytes and achieved gene silencing even after crossing an in vitro bloodbrain-barrier model [61]. Gonzalo et al. investigated the ability of dendrimer 2G-NN16 to transfect versatile cell types and to inhibit HIV replication. Low cytotoxicity was detected in a variety of cells after 2G-NN16 treatment and imaging of cellular uptake showed high transfection efficiency of siRNA in all cells tested. The dendrimer/siRNA complexes exhibited therapeutic potential by specifically inhibiting cyclooxygenase-2 gene expression in HIV-infected nervous system cells [62]. In 2011 Shcharbin et al. investigated complex formation between 2G-NN8/2G-NN16 (Figure 5) and antiHIV siRNA siGAG1. Addition of dendrimers increased the zeta potential of siGAG1 and slightly increased the size of the complex, and the 2G-NN16 dendrimer interacted more strongly with siRNA than 2G-NN8 [63]. Recently, Ionov et al. studied the interaction of the carbosilane dendrimers/siRNA dendriplex with large unilamellar vesicles (LUV). Two kinds of dendrimers with branches of carbonsilicon bonds (CBD-CS) or oxygen-silicon bonds (CBDOS) were compared. CBD-CS decreased the zeta potential values of LUVs to more negative ones, whereas an increase effect was observed in CBD-OS case, due to different kind of interaction between LUVs and the dendriplexes [64].

\section{Poly(I-lysine) Dendrimers}

Poly(L-lysine) (PLL) dendrimers (Figure 6) have also been developed as nonviral vectors for siRNA delivery [65-67]. In 2008 Inoue et al. studied the potential of PLL G6 dendrimer to be a candidate as siRNA carrier. PLL dendrimers showed effective knockdown of GAPDH with low cytotoxicity in combination with a weak-base amphiphilic peptide EndoPorter. In addition, the knockdown of PEPCK, a rate-limiting enzyme for gluconeogenesis, caused a decrease in glucose production in rat hepatoma H4IIEC3 cells and that the knockdown of organic cation transporter 1 (OCT1) diminished the ability of metformin to inhibit gluconeogenesis in H4IIEC3 cells [65]. Later Watanabe et al. showed that intravenous delivery of apolipoprotein B (ApoB)-specific siRNA with a PLL G6 dendrimer led to knockdown of ApoB in healthy mice without hepatotoxicity [66]. In 2009 Kaneshiro and Lu developed a new class of poly(L-lysine) 


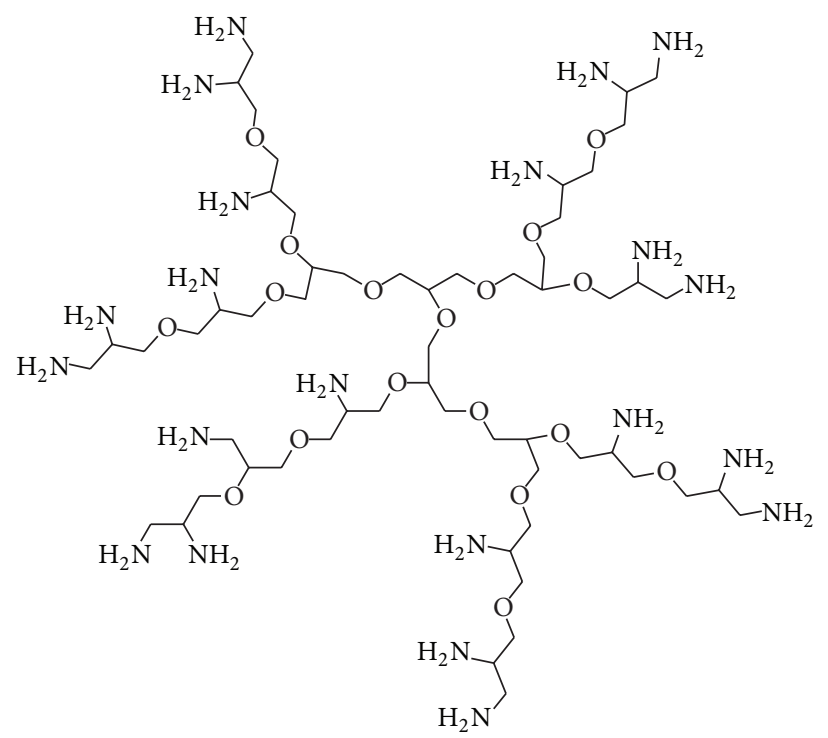

(a)

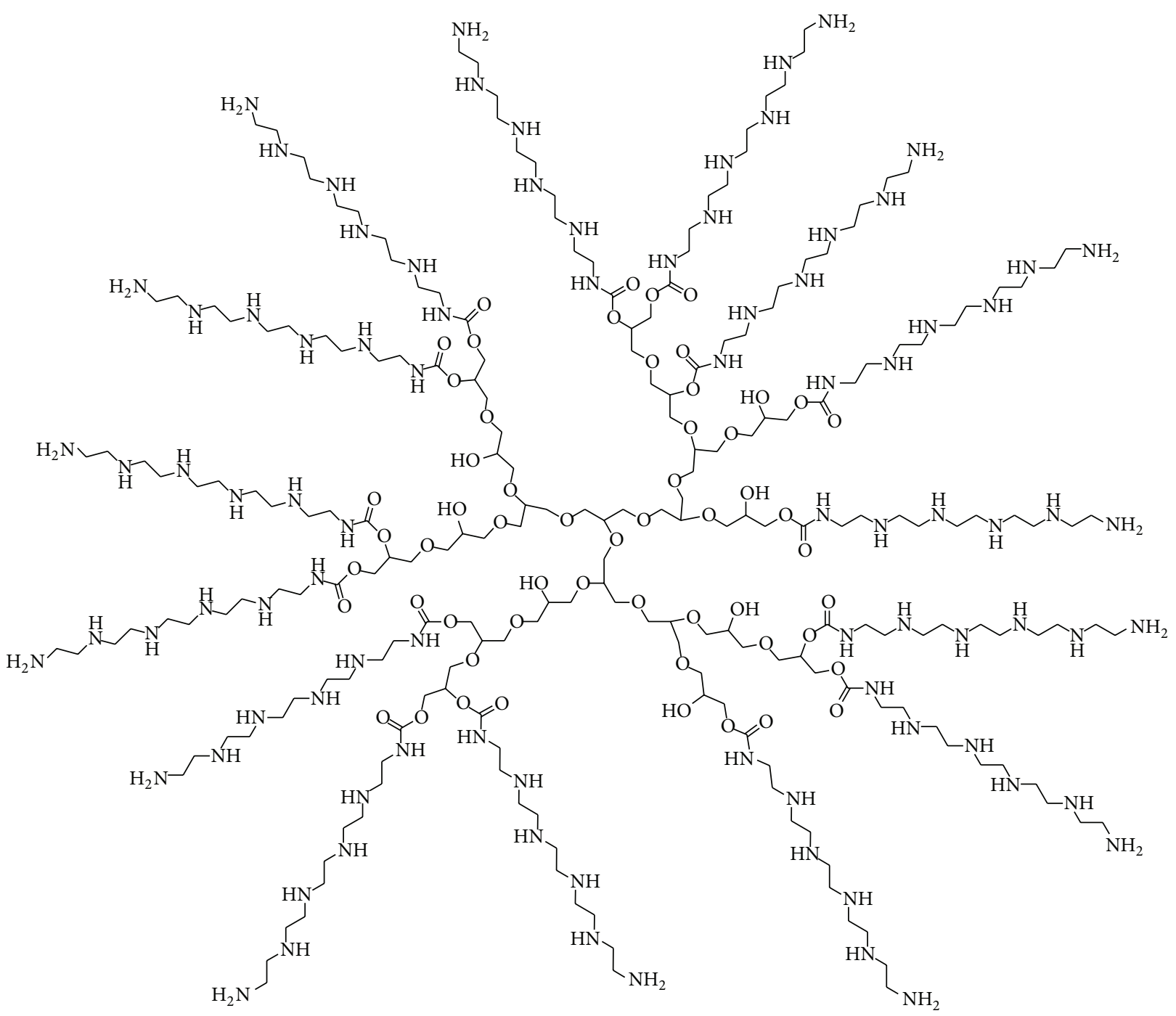

(b)

Figure 8: Polyglycerol derived dendrimers. (a) PG-NH $\mathrm{NH}_{2}$; (b) PG-PEHA. 


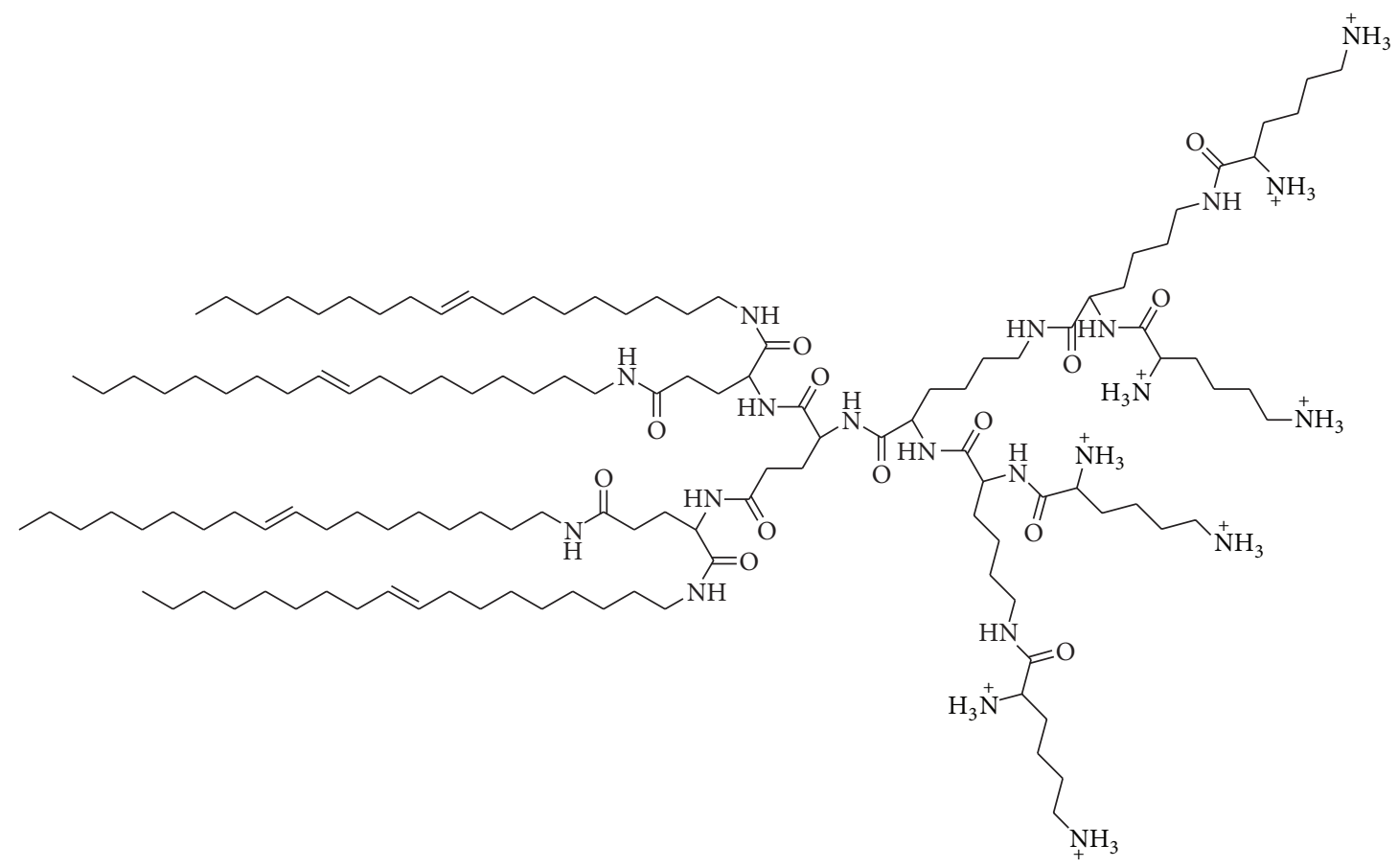

Figure 9: Tetra-oleoyl lysine (TOL) G3 dendrimer.

dendrimers with a silsesquioxane cubic core, termed as nanoglobules. A G3 nanoglobular dendrimer was used to conjugate a peptide $\mathrm{c}(\mathrm{RGDfK})$ with a PEG spacer to deliver both DOX and siRNA. G3-[PEG-RGD]-[DOX] was prepared by coupling DOX to the RGD targeted nanoglobule and was further complexed with siRNA. These PLL/siRNA complexes were internalized by U87 cells and showed much higher gene silencing efficiency in U87-Luc cells than those of control conjugates G3-[PEG-RGD] and G3-[DOX] [67].

\section{Triazine Dendrimers}

In 2010 Merkel et al. synthesized a family of triazine dendrimers (Figure 7), differing in their core flexibility, generation number, and surface functionality [68]. The structure of the backbone was found to significantly influence siRNA transfection efficiency. The G2 "rigid" dendrimers showed higher gene knockdown than the "flexible" analogues while maintaining less off-target effects than Lipofectamine. In addition, the dendrimers having arginine-like exteriors or hydrophobic surface functionalities displayed the most effective gene knockdown [68]. Pavan et al. studied the interactions between DNA and siRNA with "flexible" and "rigid" G2 triazine dendrimers by computational simulation. The structure with higher flexibility resulted in a more compacted and rigid sphere-like conformation which weakened contacts with siRNA in solution. The binding with siRNA was favored over DNA due to the higher rigidity of DNA and to the consistent curvature of siRNA [69]. In 2011, Merkel et al. tried to develop siRNA delivery carriers based on flexible G2G4 triazine dendrimers by correlating physicochemical and biological properties of the complexes with thermodynamic parameters calculated using molecular modeling. While the G4 dendrimer interacted more superficially with siRNA, G2, and G3 virtually coalesced with siRNA, forming a tightly intertwined structure. All dendrimers were less toxic than polyethylenimine (PEI) and were efficiently endocytosed and showed specific luciferase knockdown in HeLa/Luc cells [70].

\section{Polyglycerol Based Dendrimers}

In 2010 Ofek et al. evaluated polyglycerol-derived dendritic structures (Figure 8), that is, polyglycerolamine $\left(\mathrm{PG}-\mathrm{NH}_{2}\right)$ and polyglyceryl pentaethylenehexamine carbamate (PGPEHA) as siRNA carriers. Cytotoxicity studies showed that these vectors exhibited a nontoxic profile at the required concentrations for gene silencing, and PG- $\mathrm{NH}_{2}$ showed higher silencing efficacy than PG-PEHA [71]. In the same year Fischer et al. reported the in vitro gene silencing properties of several polyglycerol-core dendrimers containing oligoamine shells, that is, PG-Spermine, PG-Spermidine, $\mathrm{PG}-\mathrm{NH}_{2}$, and PG-PEHA, by using a human epithelial carcinoma cell (HeLaS3) line with different proteins [72]. Dendrimer/siRNA complexes formed from PG-NH $\mathrm{N}_{2}$ and PG-PEHA exhibited similar knockdown efficiencies as a commercial lipidbased transfection reagent, HiPerFect, with low cytotoxicity. Among all the PG-derived dendrimers, PG-PEHA, which has the highest density of amines at the surface, displayed the best balance between transfection and toxicity. $\mathrm{PG}-\mathrm{NH}_{2}$, however, showed the best transfection/toxicity ratio owing to the high degree of siRNA binding [72]. In 2012 Malhotra et al. developed amphiphilic polyglycerol dendron based amphiphiles with a hydrophobic C-18 alkyl chain at the core and multiple amine groups on its surface. The results showed 


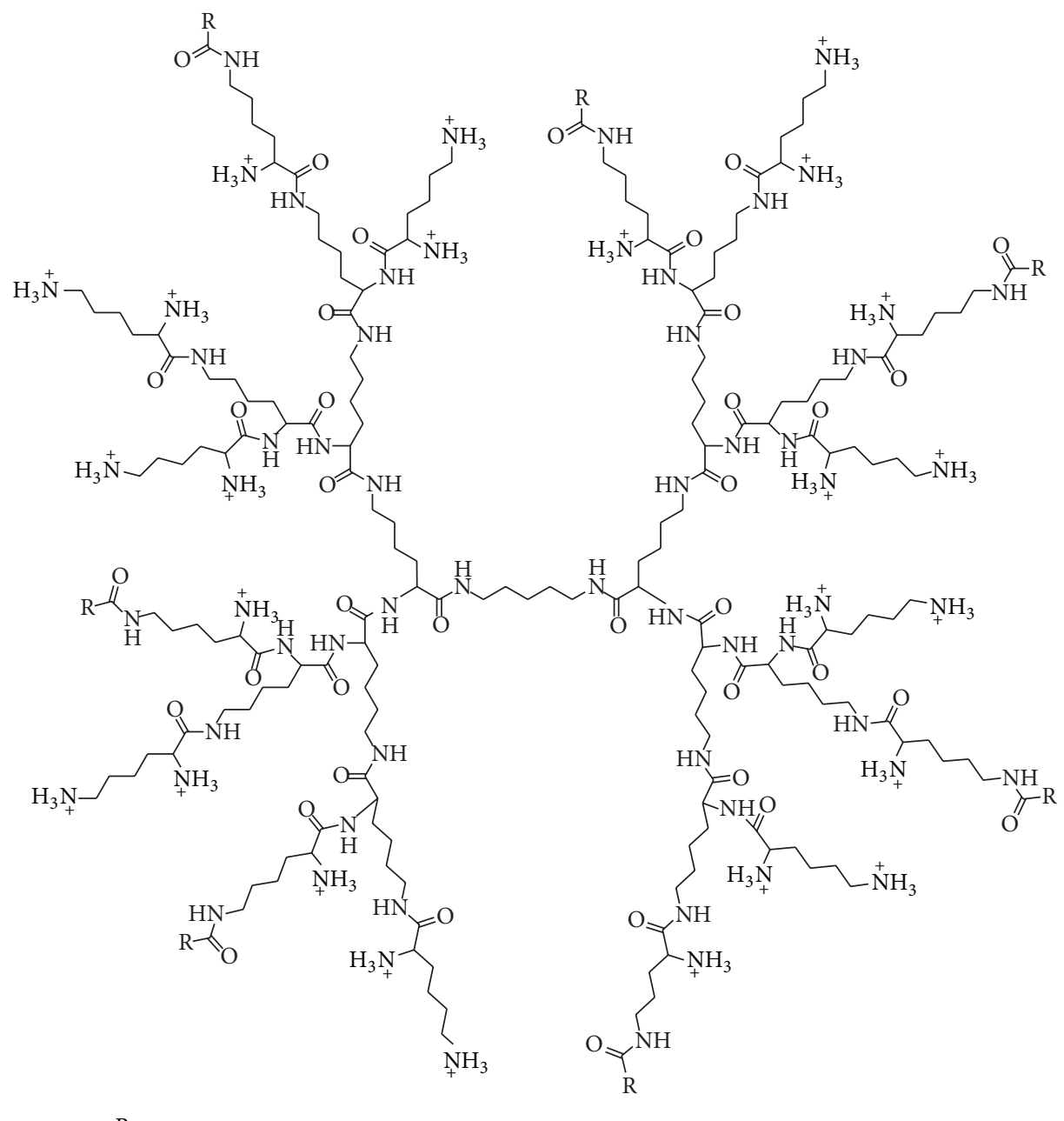

$\mathrm{R}=\mathrm{N}^{\mathrm{N}}$

(a)

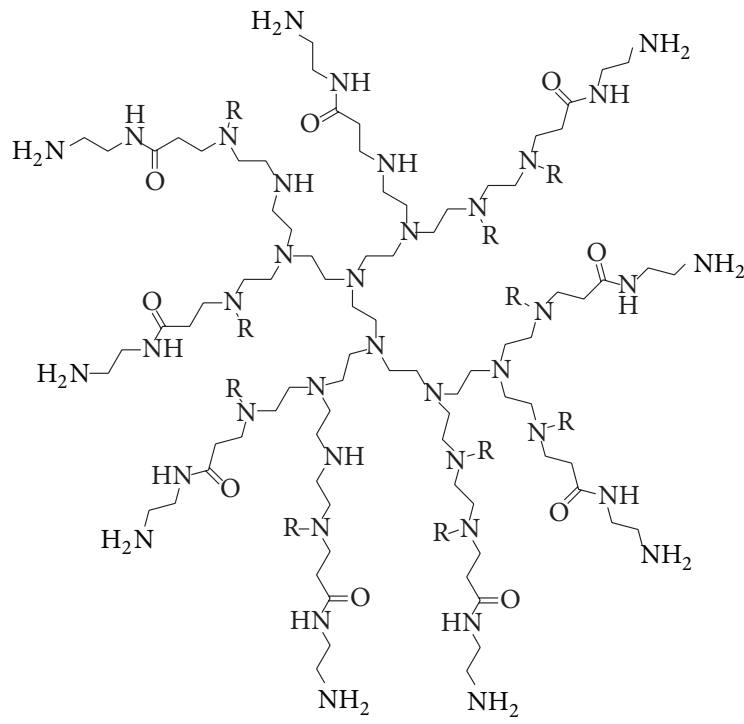

(c)

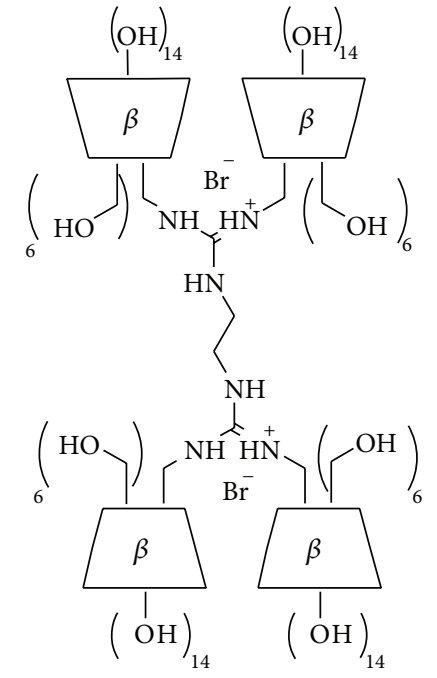

(b)

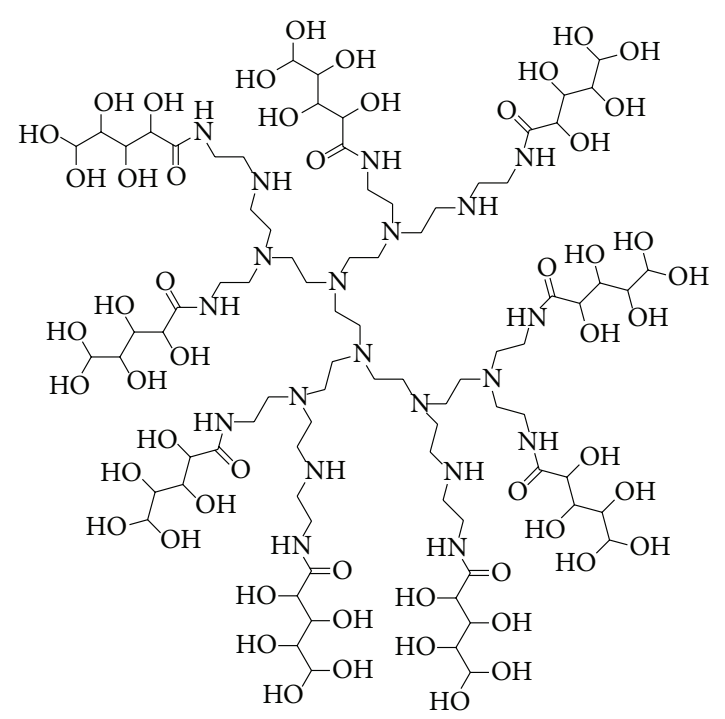

(d)

FIGURE 10: Other types of dendrimers. (a) Dendrimer-lipid component for iNOPs; (b) cyclodextrin tetrapod; (c) PEI-PAMAM; (d) PEI-Glu. 
that G2 dendrimer could efficiently downregulate luciferase and GAPDH gene activity in HeLa cells with quite low cytotoxicity [73].

\section{Nanocarbon-Containing Dendrimers}

In 2009 Herrero et al. prepared a series of dendron-functionalized multiwalled carbon nanotube (MWNT) derivatives as vectors for siRNA delivery. These MWNT derivatives had positively charged tetraalkylammonium salts at the surface which promoted carbon nanotubes to penetrate cell membranes. The delivery of the siRNA into the cytoplasm was increased throughout all the dendron generations [74]. Later, McCarroll et al. fabricated a siRNA delivery system based on modified single-walled carbon nanotube (SWNT) for gene silencing. SWNT was functionalized with tetraoleoyl lysine (TOL) dendrimers (Figure 9) and complexed to siRNA. After injection of SWNT-dendrimer/siRNA complex in mice, an endogenous gene for $A p o B$ was silenced in liver with plasma levels of ApoB and cholesterol decreased. About $80 \%$ of the RNA molecules assembled with SWNTdendrimer conjugates were cleared from the body $48 \mathrm{~h}$ after injection, suggesting that the carbon nanotubes did not inhibit siRNA biodegradation and clearance [75]. In 2012, a hybrid system composed of PAMAM-functionalized carbon nanohorns was prepared by Guerra et al. and was shown to be able to downregulate the level of house-keeping GAPDH mRNA and p42-MAPK protein [76]. Later, PérezMartínez et al. employed this hybrid material to knockdown cofilin-1, a key protein in the regulation of cellular cytoskeleton, to human prostate cancer cells and to potentiate the cytotoxic actions of anticancer drug such as Docetaxel [77].

\section{Other Types of Dendrimers}

In 2007 Baigude et al. reported the design and preparation of interfering nanoparticles (iNOPs) as siRNA delivery reagents. The iNOPs had two subunits: a functionalized dendrimer-lipid nanoparticle as the carrier (Figure 10(a)) and a chemically modified siRNA for silencing. After injection of iNOPs into mice, gene silencing was observed with an endogenous gene for apolipoprotein $\mathrm{B}$. In addition, the iNOP treatment did not cause an immune response [78]. In 2008, Menuel et al. described the synthesis of bis-(guanidinium)tetrakis-( $\beta$-cyclodextrin) tetrapod (Figure $10(\mathrm{~b})$ ) and the ability of this reagent to form complex with siRNA. The cellular transfection of siRNA into human embryonic lung fibroblasts was observed by fluorescence microscopy [79]. Later, Agrawal et al. developed dendrimer-conjugated magnetofluorescent nanoworms, termed as dendriworms, as a platform for siRNA delivery. Amine-modified, cross-linked iron oxide nanoworms were conjugated with thiol-containing core PAMAM dendrons using the heterobifunctional linker $\mathrm{N}$-succinimidyl 3-(2-pyridyldithio)-propionate. The dendriworms complex containing siRNA against the epidermal growth factor receptor reduced protein levels of EGFR in human glioblastoma cells, 2.5-fold more efficiently than commercial cationic lipids [80]. In 2010, Ofek et al. prepared PEI-derived dendritic structures with polyamidoamine (PEIPAMAM) or gluconolactone (PEI-Glu) as the shell (Figures 10(c) and 10(d)). PEI-Glu was more biocompatible than PEI-PAMAM and siRNA-PEI-Glu complexes successfully accumulated in the cytoplasm in a time-dependent manner. However, the gene silencing efficiency of PEI-PAMAM was higher than PEI-Glu [71]. Recently, Briz et al. evaluated a phosphorus-containing dendrimer for siRNA delivery. Using specific siRNA against HIV-1 Nef, the siRNA/dendrimer dendriplex showed efficient Nef silencing to interfere in HIV1 replication [81].

\section{Conclusion}

Gene therapy has gained significant attentions over the past two decades since it provides promising method for treating cancers as well as genetic disorders. In particular, RNAi is more and more popular for gene targeting and gene silencing both in laboratory research and as clinical therapeutic due to its high efficacy and specificity. However, to identify efficient and safe vectors to deliver siRNA for successful RNAi process remains the major challenge, both in vitro and in vivo. Considering the safety issues and other drawbacks of viral approach, the nonviral vectors for siRNA delivery are increasingly concerned as the alternatives of viral ones. Among versatile non-viral vectors, dendrimer-based siRNA carriers have been gradually explored since their performance in DNA delivery was approved. As demonstrated in the context, there are lots of dendritic molecules developed to deliver siRNA, while PAMAM dendrimers are most investigated owing to the facility of synthesis and modification and the commercial availability. There are basically three means to optimize the dendrimer structure for lowering the cytotoxicity as well as improving the delivering efficiency: (1) synthesis of new dendritic structure or use new core unit for dendrimer preparation, (2) functionalization of the interior or exterior part of dendrimer molecules, and (3) employing other biocompatible/bioactive molecules to form effective complexes with dendrimers. Since different cell lines have different requirement for the delivery system, one should be very careful, when studying dendrimer-base siRNA delivery, to choose the proper dendrimer structure, the optimizing method and the delivery condition depending on the type of targeting gene as well as the cells to be transferred. Today, more and more scientists are working on dendrimers for efficient delivery of siRNA. With a combination of research data from extensive work and the experience in commercializing DNA delivery reagent, we can envisage the prospective of dendrimer-base practical product for siRNA delivery in future.

\section{Acknowledgments}

This work was supported by the National Natural Science Foundation of China (no. 51003081). Note that all original publications have not been cited due to the literature source and reference limitation. 


\section{References}

[1] A. Fire, S. Xu, M. K. Montgomery, S. A. Kostas, S. E. Driver, and C. C. Mello, "Potent and specific genetic interference by doublestranded RNA in caenorhabditis elegans," Nature, vol. 391, no. 6669, pp. 806-811, 1998.

[2] S. M. Hammond, S. Boettcher, A. A. Caudy, R. Kobayashi, and G. J. Hannon, "Argonaute2, a link between genetic and biochemical analyses of RNAi," Science, vol. 293, no. 5532, pp. 1146-1150, 2001.

[3] L. Aagaard and J. J. Rossi, "RNAi therapeutics: principles, prospects and challenges," Advanced Drug Delivery Reviews, vol. 59, no. 2-3, pp. 75-86, 2007.

[4] J. Wang, Z. Lu, M. G. Wientjes, and J. L.-S. Au, "Delivery of siRNA therapeutics: barriers and carriers," AAPS Journal, vol. 12, no. 4, pp. 492-503, 2010.

[5] X. Liu, P. Rocchi, and L. Peng, "Dendrimers as non-viral vectors for siRNA delivery," New Journal of Chemistry, vol. 36, no. 2, pp. 256-263, 2012.

[6] A. P. Perez, E. L. Romero, and M. J. Morilla, "Ethylendiamine core PAMAM dendrimers/siRNA complexes as in vitro silencing agents," International Journal of Pharmaceutics, vol. 380, no. 1-2, pp. 189-200, 2009.

[7] A. P. Perez, M. L. Cosaka, E. L. Romero, and M. J. Morilla, "Uptake and intracellular traffic of siRNA dendriplexes in glioblastoma cells and macrophages," International Journal of Nanomedicine, vol. 6, pp. 2715-2728, 2011.

[8] A. P. Perez, C. Mundina-Weilenmann, E. L. Romero, and M. J. Morilla, "Increased brain radioactivity by intranasal 32Plabeled siRNA dendriplexes within in situ-forming mucoadhesive gels," International Journal of Nanomedicine, vol. 7, pp. 13731385, 2012.

[9] L. B. Jensen, G. M. Pavan, M. R. Kasimova et al., "Elucidating the molecular mechanism of PAMAM-siRNA dendriplex selfassembly: effect of dendrimer charge density," International Journal of Pharmaceutics, vol. 416, no. 2, pp. 410-418, 2011.

[10] L. B. Jensen, J. Griger, B. Naeye et al., "Comparison of polymeric siRNA nanocarriers in a murine LPS-activated macrophage cell line: gene silencing, toxicity and off-target gene expression," Pharmaceutical Research, vol. 29, no. 3, pp. 669-682, 2012.

[11] S. Monteagudo, F. C. Pérez-Martínez, M. D. Pérez-Carrión et al., "Inhibition of p42 MAPK using a nonviral vectordelivered siRNA potentiates the anti-tumor effect of metformin in prostate cancer cells," Nanomedicine, vol. 7, pp. 493-506, 2012.

[12] A. J. Hollins, Y. Omidi, I. F. Benter, and S. Akhtar, "Toxicogenomics of drug delivery systems: exploiting delivery systeminduced changes in target gene expression to enhance siRNA activity," Journal of Drug Targeting, vol. 15, no. 1, pp. 83-88, 2007.

[13] H. Kang, R. DeLong, M. H. Fisher, and R. L. Juliano, "Tatconjugated PAMAM dendrimers as delivery agents for antisense and siRNA oligonucleotides," Pharmaceutical Research, vol. 22, no. 12, pp. 2099-2106, 2005.

[14] T. Tsutsumi, H. Arima, F. Hirayama, and K. Uekama, "Potential use of dendrimer $/ \alpha$-cyclodextrin conjugate as a novel carrier for small interfering RNA, (siRNA)," Journal of Inclusion Phenomena and Macrocyclic Chemistry, vol. 56, no. 1-2, pp. 81-84, 2006.

[15] T. Tsutsumi, F. Hirayama, K. Uekama, and H. Arima, "Evaluation of polyamidoamine dendrimer $/ \alpha$-cyclodextrin conjugate (generation 3, G3) as a novel carrier for small interfering RNA (siRNA)," Journal of Controlled Release, vol. 119, no. 3, pp. 349359, 2007.
[16] H. Arima, T. Tsutsumi, A. Yoshimatsu et al., "Inhibitory effect of siRNA complexes with polyamidoamine dendrimer $/ \alpha$ cyclodextrin conjugate (generation $3, \mathrm{G} 3$ ) on endogenous gene expression," European Journal of Pharmaceutical Sciences, vol. 44, no. 3, pp. 375-384, 2011.

[17] H. Arima, A. Yoshimatsu, H. Ikeda et al., "Folate-PEGappended dendrimer conjugate with $\alpha$-cyclodextrin as a novel cancer cell-selective siRNA delivery carrier," Molecular Pharmaceutics, vol. 9, no. 9, pp. 2591-2604, 2012.

[18] Y. Hayashi, Y. Mori, S. Yamashita et al., "Potential use of lactosylated dendrimer $(\mathrm{G} 3) / \alpha$-cyclodextrin conjugates as hepatocytespecific siRNA carriers for the treatment of familial amyloidotic polyneuropathy," Molecular Pharmaceutics, vol. 9, no. 6, pp. 1645-1653, 2012.

[19] Y. Hayashi, Y. Mori, T. Higashi et al., "Systemic delivery of transthyretin siRNA mediated by lactosylated dendrimer/ alpha-cyclodextrin conjugates into hepatocyte for familial amyloidotic polyneuropathy therapy," Amyloid, vol. 19, supplement 1, pp. 47-49, 2012.

[20] M. L. Patil, M. Zhang, S. Betigeri, O. Taratula, H. He, and T. Minko, "Surface-modified and internally cationic polyamidoamine dendrimers for efficient siRNA delivery," Bioconjugate Chemistry, vol. 19, no. 7, pp. 1396-1403, 2008.

[21] M. L. Patil, M. Zhang, O. Taratula, O. B. Garbuzenko, H. He, and T. Minko, "Internally cationic polyamidoamine PAMAM$\mathrm{OH}$ dendrimers for siRNA delivery: effect of the degree of quaternization and cancer targeting," Biomacromolecules, vol. 10, no. 2, pp. 258-266, 2009.

[22] M. L. Patil, M. Zhang, and T. Minko, "Multifunctional triblock nanocarrier (PAMAM-PEG-PLL) for the efficient intracellular siRNA delivery and gene silencing," ACS Nano, vol. 5, no. 3, pp. 1877-1887, 2011.

[23] C. L. Waite, S. M. Sparks, K. E. Uhrich, and C. M. Roth, "Acetylation of PAMAM dendrimers for cellular delivery of siRNA," BMC Biotechnology, vol. 9, article 38, 10 pages, 2009.

[24] C. L. Waite and C. M. Roth, "PAMAM-RGD conjugates enhance siRNA delivery through a multicellular spheroid model of malignant glioma," Bioconjugate Chemistry, vol. 20, no. 10, pp. 1908-1916, 2009.

[25] C. L. Waite and C. M. Roth, "Binding and transport of PAMAMRGD in a tumor spheroid model: the effect of RGD targeting ligand density," Biotechnology and Bioengineering, vol. 108, no. 12, pp. 2999-3008, 2011.

[26] M. Elsabahy, N. Wazen, N. Bayó-Puxan et al., "Delivery of nucleic acids through the controlled disassembly of multifunctional nanocomplexes," Advanced Functional Materials, vol. 19, no. 24, pp. 3862-3867, 2009.

[27] A. E. Felber, B. Castagner, M. Elsabahy, G. F. Deleavey, M. J. Damha, and J.-C. Leroux, "SiRNA nanocarriers based on methacrylic acid copolymers," Journal of Controlled Release, vol. 152, no. 1, pp. 159-167, 2011.

[28] Q. Yuan, E. Lee, W. A. Yeudall, and H. Yang, "Dendrimertriglycine-EGF nanoparticles for tumor imaging and targeted nucleic acid and drug delivery," Oral Oncology, vol. 46, no. 9, pp. 698-704, 2010.

[29] T. Dutta, M. Burgess, N. A. J. McMillan, and H. S. Parekh, "Dendrosome-based delivery of siRNA against E6 and E7 oncogenes in cervical cancer," Nanomedicine, vol. 6, no. 3, pp. 463-470, 2010.

[30] I.-D. Kim, C.-M. Lim, J.-B. Kim et al., "Neuroprotection by biodegradable PAMAM ester (e-PAM-R)-mediated HMGB1 
siRNA delivery in primary cortical cultures and in the postischemic brain," Journal of Controlled Release, vol. 142, no. 3, pp. 422-430, 2010.

[31] I.-D. Kim, J.-H. Shin, S.-W. Kim et al., "Intranasal delivery of HMGB1 siRNA confers target gene knockdown and robust neuroprotection in the postischemic brain," Molecular Therapy, vol. 20, no. 4, pp. 829-839, 2012.

[32] J. Liu, J. Zhou, and Y. Luo, "SiRNA delivery systems based on neutral cross-linked dendrimers," Bioconjugate Chemistry, vol. 23, no. 2, pp. 174-183, 2012.

[33] Y. Tang, Y. B. Li, B. Wang et al., "Efficient in vitro siRNA delivery and intramuscular gene silencing using PEG-modified PAMAM dendrimers," Molecular Pharmaceutics, vol. 9, no. 6, pp. 1812-1821, 2012.

[34] M. Han, Q. Lv, X.-J. Tang et al., "Overcoming drug resistance of MCF-7/ADR cells by altering intracellular distribution of doxorubicin via MVP knockdown with a novel siRNA polyamidoamine-hyaluronic acid complex," Journal of Controlled Release, vol. 163, no. 2, pp. 136-144, 2012.

[35] X.-C. Shen, J. Zhou, X. Liu et al., "Importance of size-tocharge ratio in construction of stable and uniform nanoscale RNA/dendrimer complexes," Organic and Biomolecular Chemistry, vol. 5, no. 22, pp. 3674-3681, 2007.

[36] J. Zhou, J. Wu, N. Hafdi, J.-P. Behr, P. Erbacher, and L. Peng, "PAMAM dendrimers for efficient siRNA delivery and potent gene silencing," Chemical Communications, no. 22, pp. 23622364,2006

[37] X.-X. Liu, P. Rocchi, F.-Q. Qu et al., "PAMAM dendrimers mediate siRNA delivery to target Hsp27 and produce potent antiproliferative effects on prostate cancer cells," ChemMedChem, vol. 4, no. 8, pp. 1302-1310, 2009.

[38] J. Zhou, C. P. Neff, X. Liu et al., "Systemic administration of combinatorial dsiRNAs via nanoparticles efficiently suppresses HIV-1 infection in humanized mice," Molecular Therapy, vol. 19, no. 12, pp. 2228-2238, 2011.

[39] X. Liu, C. Liu, E. Laurini et al., "Efficient delivery of sticky siRNA and potent gene silencing in a prostate cancer model using a generation 5 triethanolamine-core PAMAM dendrimer," Molecular Pharmaceutics, vol. 9, no. 3, pp. 470-481, 2012.

[40] T. Z. Yu, X. X. Liu, A. L. Bolcato-Bellemin et al., "An amphiphilic dendrimer for effective delivery of small interfering RNA and gene silencing in vitro and in vivo," Angewandte Chemie International Edition, vol. 51, no. 34, pp. 8478-8484, 2012.

[41] J. Deng, N. Li, K. Mai, C. Yang, L. Yan, and L.-M. Zhang, "Star-shaped polymers consisting of a $\beta$-cyclodextrin core and poly(amidoamine) dendron arms: binding and release studies with methotrexate and siRNA," Journal of Materials Chemistry, vol. 21, no. 14, pp. 5273-5281, 2011.

[42] A. C. Rodrigo, I. Rivilla, F. C. Perez-Martinez et al., "Efficient, non-toxic hybrid PPV-PAMAM dendrimer as a gene carrier for neuronal cells," Biomacromolecules, vol. 12, no. 4, pp. 1205-1213, 2011.

[43] M. D. Pérez-Carrión, F. C. Perez-Martínez, S. Merino et al., "Dendrimer-mediated siRNA delivery knocks down Beclin 1 and potentiates NMDA-mediated toxicity in rat cortical neurons," Journal of Neurochemistry, vol. 120, no. 2, pp. 259-268, 2012.

[44] G. M. Pavan, S. Monteagudo, J. Guerra et al., "Role of generation, architecture, $\mathrm{pH}$ and ionic strength on successful siRNA delivery and transfection by hybrid PPV-PAMAM Dendrimers," Current Medicinal Chemistry, vol. 19, no. 29, pp. 49294941, 2012.
[45] Y. Zhang, C. Zhou, K. J. Kwak et al., "Efficient siRNA delivery using a polyamidoamine dendrimer with a modified pentaerythritol core," Pharmaceutical Research, vol. 29, no. 6, pp. 16271636, 2012.

[46] P. Posocco, G. M. Pavan, G. Scocchi et al., "Base invaders. Coupling experiments and multiscale modeling of dendrimer-based siRNA delivery agents," Advances in Science and Technology, vol. 57, pp. 154-159, 2008.

[47] V. Vasumathi and P. K. Maiti, "Complexation of siRNA with dendrimer: a molecular modeling approach," Macromolecules, vol. 43, no. 19, pp. 8264-8274, 2010.

[48] G. M. Pavan, P. Posocco, A. Tagliabue et al., "PAMAM dendrimers for siRNA delivery: computational and experimental insights," Chemistry, vol. 16, no. 26, pp. 7781-7795, 2010.

[49] G. M. Pavan, L. Albertazzi, and A. Danani, "Ability to adapt: different generations of PAMAM dendrimers show different behaviors in binding siRNA," Journal of Physical Chemistry B, vol. 114, no. 8, pp. 2667-2675, 2010.

[50] L. B. Jensen, K. Mortensen, G. M. Pavan et al., "Molecular characterization of the interaction between siRNA and PAMAM G7 dendrimers by SAXS, ITC, and molecular dynamics simulations," Biomacromolecules, vol. 11, no. 12, pp. 3571-3577, 2010.

[51] K. Karatasos, P. Posocco, E. Laurini, and S. Pricl, "Poly (amidoamine)-based dendrimer/siRNA complexation studied by computer simulations: effects of $\mathrm{pH}$ and generation on dendrimer structure and siRNA binding," Macromolecular Bioscience, vol. 12, no. 2, pp. 225-240, 2012.

[52] B. Nandy, M. Santosh, and P. K. Maiti, "Interaction of nucleic acids with carbon nanotubes and dendrimers," Journal of Biosciences, vol. 37, no. 3, pp. 457-474, 2012.

[53] O. Taratula, O. B. Garbuzenko, P. Kirkpatrick et al., "Surfaceengineered targeted PPI dendrimer for efficient intracellular and intratumoral siRNA delivery," Journal of Controlled Release, vol. 140, no. 3, pp. 284-293, 2009.

[54] A. M. Chen, O. Taratula, D. Wei et al., "Labile catalytic packaging of DNA/siRNA: control of gold nanoparticles "out" of DNA/siRNA complexes," ACS Nano, vol. 4, no. 7, pp. 36793688, 2010.

[55] O. Taratula, R. Savla, H. He, and T. Minko, "Poly(propyleneimine) dendrimers as potential siRNA delivery nanocarrier: from structure to function," International Journal of Nanotechnology, vol. 8, no. 1-2, pp. 36-52, 2011.

[56] O. Taratula, O. Garbuzenko, R. Savla, Y. A. Wang, H. He, and T. Minko, "Multifunctional nanomedicine platform for cancer specific delivery of sirna by superparamagnetic iron oxide nanoparticles-dendrimer complexes," Current Drug Delivery, vol. 8, no. 1, pp. 59-69, 2011.

[57] J. L. Jiménez, R. Gómez, V. Briz et al., "Carbosilane dendrimers as carriers of siRNA," Journal of Drug Delivery Science and Technology, vol. 22, no. 1, pp. 75-82, 2012.

[58] N. Weber, P. Ortega, M. I. Clemente et al., "Characterization of carbosilane dendrimers as effective carriers of siRNA to HIVinfected lymphocytes," Journal of Controlled Release, vol. 132, no. 1, pp. 55-64, 2008.

[59] R. Gras, L. Almonacid, P. Ortega et al., "Changes in gene expression pattern of human primary macrophages induced by carbosilane dendrimer 2G-NN16," Pharmaceutical Research, vol. 26, no. 3, pp. 577-586, 2009.

[60] I. Posadas, B. López-Hernández, M. I. Clemente et al., "Highly efficient transfection of rat cortical neurons using carbosilane dendrimers unveils a neuroprotective role for HIF-1 $\alpha$ in 
early chemical hypoxia-mediated neurotoxicity," Pharmaceutical Research, vol. 26, no. 5, pp. 1181-1191, 2009.

[61] J. L. Jimnez, M. I. Clemente, N. D. Weber et al., "Carbosilane dendrimers to transfect human astrocytes with small interfering RNA targeting human immunodeficiency virus," BioDrugs, vol. 24, no. 5, pp. 331-343, 2010.

[62] T. Gonzalo, M. I. Clemente, L. Chonco et al., "Gene therapy in HIV-infected cells to decrease viral impact by using an alternative delivery method," ChemMedChem, vol. 5, no. 6, pp. 921-929, 2010.

[63] D. Shcharbin, E. Pedziwiatr, O. Nowacka et al., "Carbosilane dendrimers NN8 and NN16 form a stable complex with siGAG1," Colloids and Surfaces B, vol. 83, no. 2, pp. 388-391, 2011.

[64] M. Ionov, Z. Garaiova, I. Waczulikova et al., "siRNA carriers based on carbosilane dendrimers affect zeta potential and size of phospholipid vesicles," Biochimica et Biophysica Acta, vol. 1818, no. 9, pp. 2209-2216, 2012.

[65] Y. Inoue, R. Kurihara, A. Tsuchida et al., "Efficient delivery of siRNA using dendritic poly(L-lysine) for loss-of-function analysis," Journal of Controlled Release, vol. 126, no. 1, pp. 5966, 2008.

[66] K. Watanabe, M. Harada-Shiba, A. Suzuki et al., "In vivo siRNA delivery with dendritic poly(L-lysine) for the treatment of hypercholesterolemia," Molecular BioSystems, vol. 5, no. 11, pp. 1306-1310, 2009.

[67] T. L. Kaneshiro and Z.-R. Lu, "Targeted intracellular codelivery of chemotherapeutics and nucleic acid with a well-defined dendrimer-based nanoglobular carrier," Biomaterials, vol. 30, no. 29, pp. 5660-5666, 2009.

[68] O. M. Merkel, M. A. Mintzer, D. Librizzi et al., “Triazine dendrimers as nonviral vectors for in vitro and in vivo RNAi: the effects of peripheral groups and core structure on biological activity," Molecular Pharmaceutics, vol. 7, no. 4, pp. 969-983, 2010.

[69] G. M. Pavan, M. A. Mintzer, E. E. Simanek, O. M. Merkel, T. Kissel, and A. Danani, "Computational insights into the interactions between DNA and siRNA with "rigid" and "flexible" triazine dendrimers," Biomacromolecules, vol. 11, no. 3, pp. 721730, 2010.

[70] O. M. Merkel, M. Zheng, M. A. Mintzer et al., "Molecular modeling and in vivo imaging can identify successful flexible triazine dendrimer-based siRNA delivery systems," Journal of Controlled Release, vol. 153, no. 1, pp. 23-33, 2011.

[71] P. Ofek, W. Fischer, M. Calderón, R. Haag, and R. SatchiFainaro, "In vivo delivery of small interfering RNA to tumors and their vasculature by novel dendritic nanocarriers," FASEB Journal, vol. 24, no. 9, pp. 3122-3134, 2010.

[72] W. Fischer, M. Calderón, A. Schulz, I. Andreou, M. Weber, and R. Haag, "Dendritic polyglycerols with oligoamine shells show low toxicity and high siRNA transfection efficiency in vitro," Bioconjugate Chemistry, vol. 21, no. 10, pp. 1744-1752, 2010.

[73] S. Malhotra, H. Bauer, A. Tschiche et al., "Glycine-terminated dendritic amphiphiles for nonviral gene delivery," Biomacromolecules, vol. 13, no. 10, pp. 3087-3098, 2012.

[74] M. A. Herrero, F. M. Toma, K. T. Al-Jamal et al., "Synthesis and characterization of a carbon nanotube-dendron series for efficient siRNA delivery," Journal of the American Chemical Society, vol. 131, no. 28, pp. 9843-9848, 2009.

[75] J. McCarroll, H. Baigude, C.-S. Yang, and T. M. Rana, "Nanotubes functionalized with lipids and natural amino acid dendrimers: a new strategy to create nanomaterials for delivering systemic RNAi," Bioconjugate Chemistry, vol. 21, no. 1, pp. 5663, 2010.

[76] J. Guerra, M. A. Herrero, B. Carrión et al., "Carbon nanohorns functionalized with polyamidoamine dendrimers as efficient biocarrier materials for gene therapy," Carbon, vol. 50, no. 8, pp. 2832-2844, 2012.

[77] F. C. Pérez-Martínez, B. Carrión, M. I. Lucío et al., "Enhanced docetaxel-mediated cytotoxicity in human prostate cancer cells through knockdown of cofilin-1 by carbon nanohorn delivered siRNA," Biomaterials, vol. 33, no. 32, pp. 8152-8159, 2012.

[78] H. Baigude, J. McCarroll, C.-S. Yang, P. M. Swain, and T. M. Rana, "Design and creation of new nanomaterials for therapeutic RNAi," ACS Chemical Biology, vol. 2, no. 4, pp. 237241, 2007.

[79] S. Menuel, S. Fontanay, I. Clarot, R. E. Duval, L. Diez, and A. Marsura, "Synthesis and complexation ability of a novel bis(guanidinium)-tetrakis- ( $\beta$-cyclodextrin) dendrimeric tetrapod as a potential gene delivery (DNA and siRNA) system. Study of cellular siRNA transfection," Bioconjugate Chemistry, vol. 19, no. 12, pp. 2357-2362, 2008.

[80] A. Agrawal, D.-H. Min, N. Singh et al., "Functional delivery of siRNA in mice using dendriworms," ACS Nano, vol. 3, no. 9, pp. 2495-2504, 2009.

[81] V. Briz, M. J. Serramia, R. Madrid et al., "Validation of a generation 4 phosphorus-containing polycationic dendrimer for gene delivery against HIV-1," Current Medicinal Chemistry, vol. 19, no. 29, pp. 5044-5051, 2012.

[82] H. Arima and K. Motoyama, "Recent findings concerning PAMAM dendrimer conjugates with cyclodextrins as carriers of DNA and RNA," Sensors, vol. 9, no. 8, pp. 6346-6361, 2009.

[83] M. Raviña, P. Paolicelli, B. Seijo, and A. Sanchez, "Knocking down gene expression with dendritic vectors," Mini-Reviews in Medicinal Chemistry, vol. 10, no. 1, pp. 73-86, 2010.

[84] F. C. Perez-Martinez, A. V. Ocana, M. D. Perez-Carrion, and V. Ceña, "Dendrimers as vectors for genetic material delivery to the nervous system," Current Medicinal Chemistry, vol. 19, no. 29, pp. 5101-5108, 2012.

[85] F. S. Mehrabadi, W. Fischer, and R. Haag, "Dendritic and lipidbased carriers for gene/siRNA delivery (a review)," Current Opinion in Solid State and Materials Science, vol. 16, no. 6, pp. 310-322, 2012.

[86] G. M. Pavan and A. Danani, "Dendrimers and dendrons for siRNA binding: computational insights," Journal of Drug Delivery Science and Technology, vol. 22, no. 1, pp. 83-89, 2012.

[87] C. Troiber and E. Wagner, "Nucleic acid carriers based on precise polymer conjugates," Bioconjugate Chemistry, vol. 22, no. 9, pp. 1737-1752, 2011.

[88] K. Singha, R. Namgung, and W. J. Kim, "Polymers in smallinterfering RNA delivery," Nucleic Acid Therapeutics, vol. 21, no. 3, pp. 133-147, 2011.

[89] E. Fattal and A. Bochot, "State of the art and perspectives for the delivery of antisense oligonucleotides and siRNA by polymeric nanocarriers," International Journal of Pharmaceutics, vol. 364, no. 2, pp. 237-248, 2008.

[90] D. Cun, L. B. Jensen, H. M. Nielsen, M. Moghimi, and C. Foged, "Polymeric nanocarriers for siRNA delivery: challenges and future prospects," Journal of Biomedical Nanotechnology, vol. 4, no. 3, pp. 258-275, 2008.

[91] E. Fattal and G. Barratt, "Nanotechnologies and controlled release systems for the delivery of antisense oligonucleotides and small interfering RNA," British Journal of Pharmacology, vol. 157, no. 2, pp. 179-194, 2009. 
[92] X. Yuan, S. Naguib, and Z. Wu, "Recent advances of siRNA delivery by nanoparticles," Expert Opinion on Drug Delivery, vol. 8, no. 4, pp. 521-536, 2011.

[93] S. Akhtar, "Cationic nanosystems for the delivery of small interfering ribonucleic acid therapeutics: a focus on toxicogenomics," Expert Opinion on Drug Metabolism and Toxicology, vol. 6, no. 11, pp. 1347-1362, 2010.

[94] K. Gao and L. Huang, "Nonviral methods for siRNA delivery," Molecular Pharmaceutics, vol. 6, no. 3, pp. 651-658, 2009.

[95] S. Akhtar and I. Benter, "Toxicogenomics of non-viral drug delivery systems for RNAi: potential impact on siRNAmediated gene silencing activity and specificity," Advanced Drug Delivery Reviews, vol. 59, no. 2-3, pp. 164-182, 2007.

[96] I. Posadas, F. J. Guerra, and V. Ceña, "Nonviral vectors for the delivery of small interfering RNAs to the CNS," Nanomedicine, vol. 5, no. 8, pp. 1219-1236, 2010.

[97] D. A. Tomalia, H. Baker, J. Dewald et al., "A new class of polymers: starburst-dendritic macromolecules," Polymer Journal, vol. 17, pp. 117-132, 1984.

[98] J. Haensler and F. C. Szoka Jr., "Polyamidoamine cascade polymers mediate efficient transfection of cells in culture," Bioconjugate Chemistry, vol. 4, no. 5, pp. 372-379, 1993.

[99] J. F. Kukowska-Latallo, A. U. Bielinska, J. Johnson, R. Spindle, D. A. Tomalia, and J. R. Baker Jr., "Efficient transfer of genetic material into mammalian cells using starburst polyamidoamine dendrimers," Proceedings of the National Academy of Sciences of the United States of America, vol. 93, no. 10, pp. 4897-4902, 1996.

[100] J. Wu, J. Zhou, F. Qu, P. Bao, Y. Zhang, and L. Peng, "Polycationic dendrimers interact with RNA molecules: polyamine dendrimers inhibit the catalytic activity of Candida ribozymes," Chemical Communications, no. 3, pp. 313-315, 2005. 

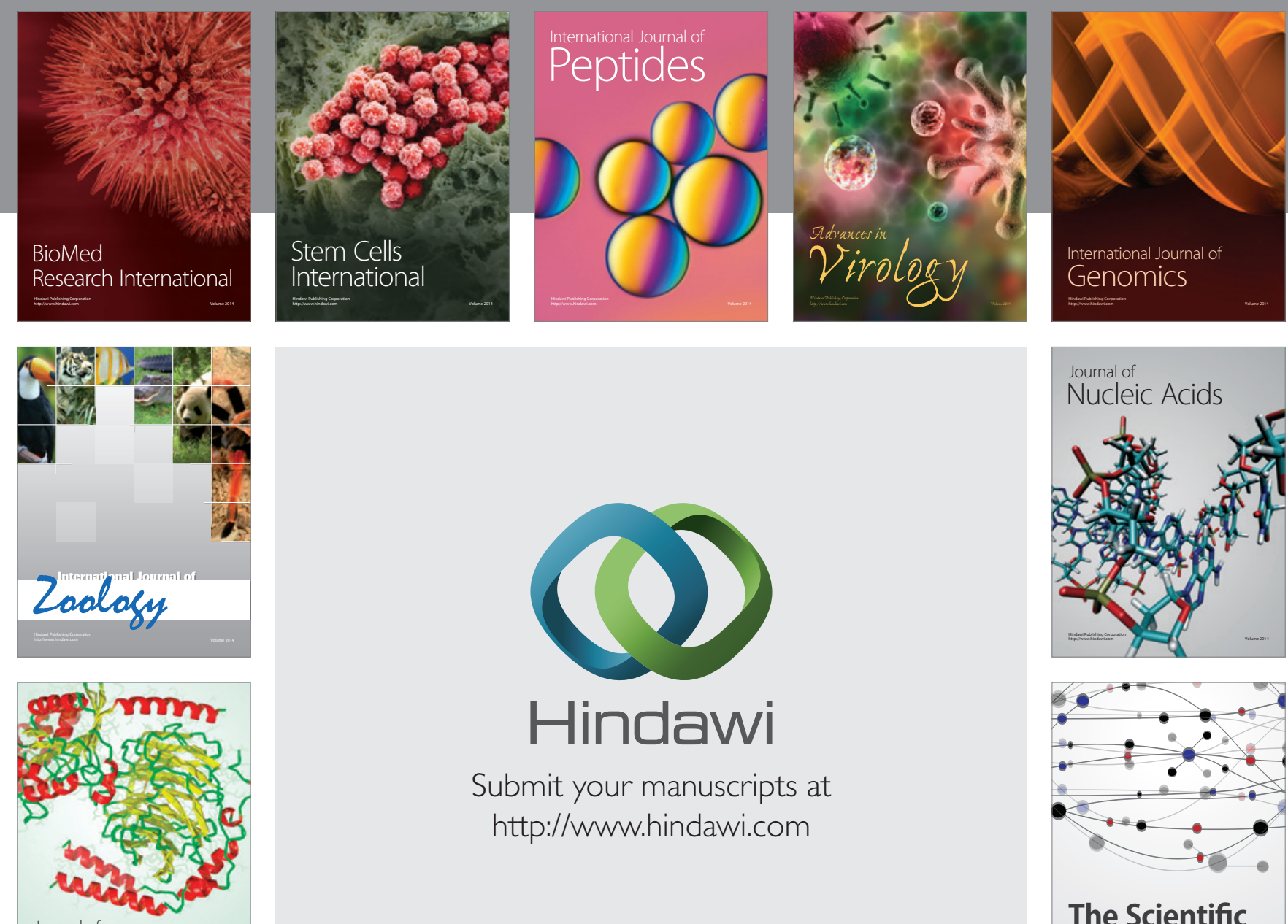

Submit your manuscripts at

http://www.hindawi.com

Journal of
Signal Transduction
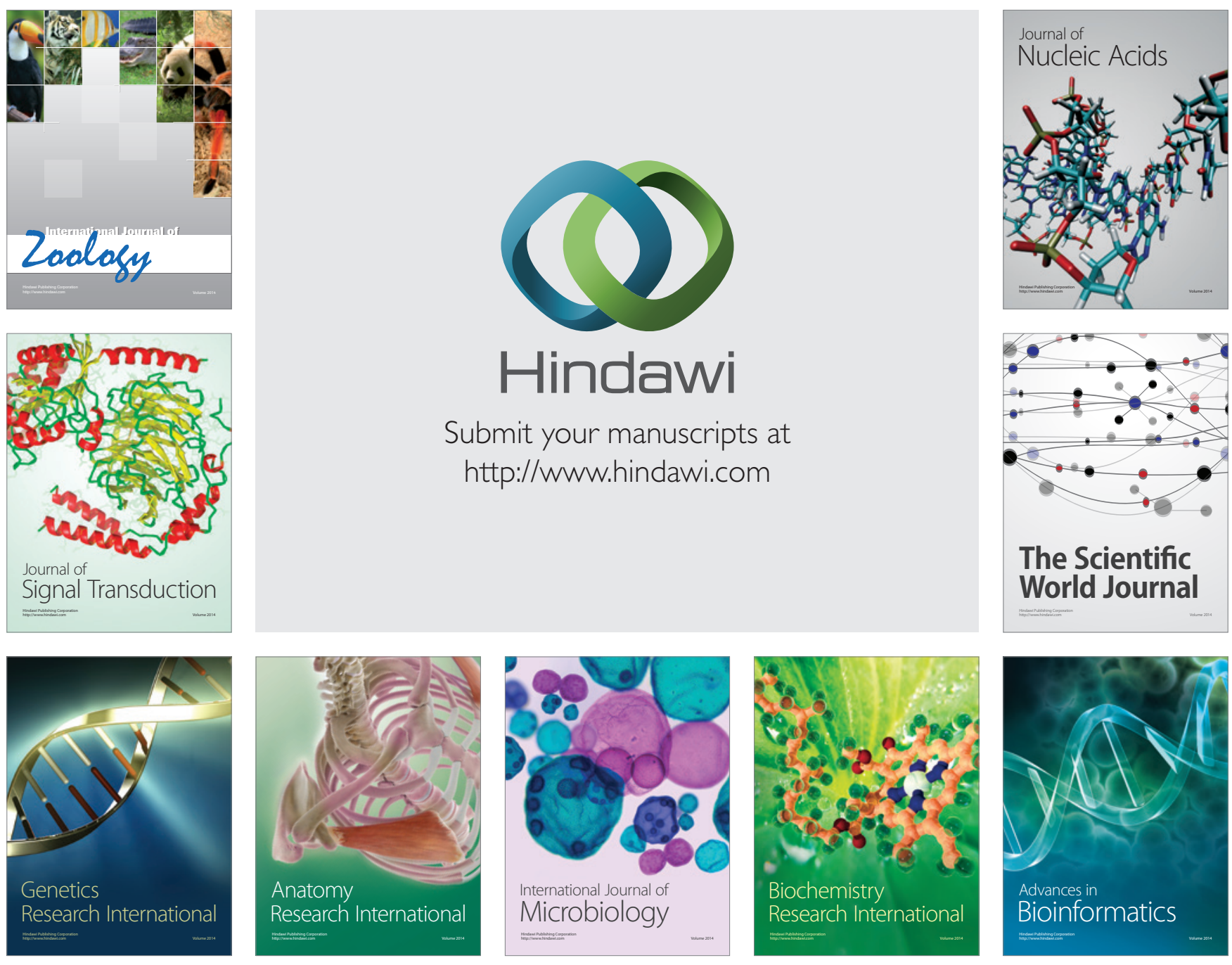

The Scientific World Journal
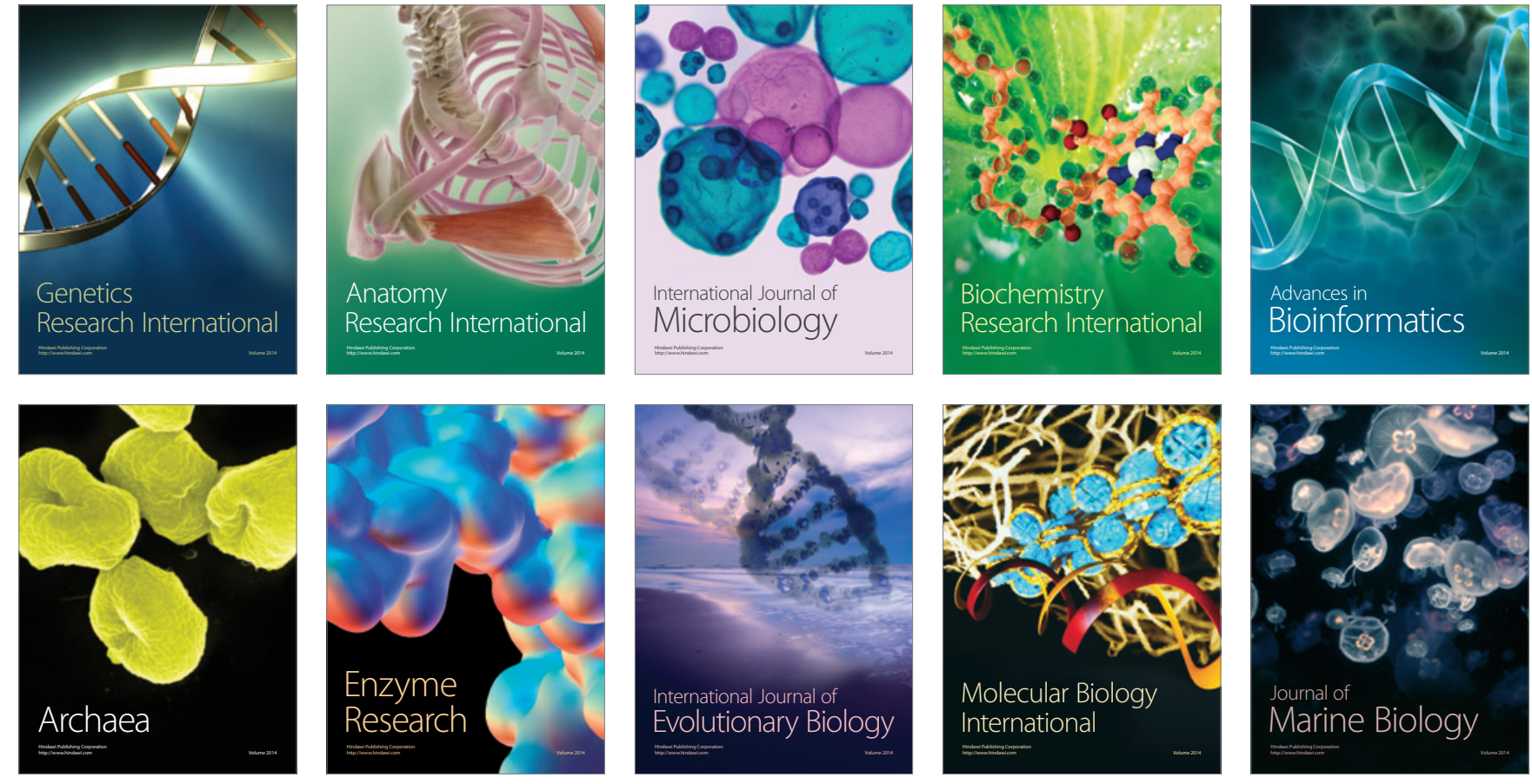